\title{
Migration and inter-generational replacement in Europe
}

\author{
Chris Wilson ${ }^{1}$, Tomáš Sobotka ${ }^{2}$, Lee Williamson ${ }^{1}$, and Paul Boyle ${ }^{1}$ \\ 1 - School of Geography and Geosciences, University of St Andrews \\ 2 - Vienna Institute of Demography, Austrian Academy of Sciences and \\ Wittgenstein Centre for Demography and Global Human Capital, Vienna \\ Contact author: Chris Wilson: ccbw@st-andrews.ac.uk
}

\section{Forthcoming in Population and Development Review, volume 38, number4, December 2012 Still subject to final editing changes}

\begin{abstract}
There are long-standing concerns over low fertility levels in Europe and an increasingly important debate on the extent to which migration can compensate for below replacement fertility. To inform this debate, a wide array of indicators that assess the joint influence of fertility, mortality, and migration on birth replacement and intergenerational replacement have been developed. These indicators are based on various models and assumptions and some are particularly data demanding. In this paper we propose a very simple method to assess how far migration alters the extent of replacement for a birth cohort as it ages. We term the measure used here the overall replacement ratio (ORR). It is calculated by taking the size of a female birth cohort at selected ages divided by the average size of the cohorts of mothers in the year of birth. The paper presents estimates of the ORR for a range of European countries representing different replacement regimes. We demonstrate that for many countries net migration has become a key factor in their population trends during the last decades.
\end{abstract}




\section{Introduction}

A population's history of fertility, mortality and migration is written into its age structure, revealing the extent to which generations are replacing themselves. In this paper we propose an easily calculated measure that enables us to track how these three processes determine the extent of inter-generational replacement. Since mortality is low in most European countries until well after the reproductive ages, it plays a very limited role in determining replacement. Therefore, in Europe, population replacement is principally influenced by the combined effects of fertility and migration.

Concern over persistent low fertility levels and observed or expected population decline in many parts of Europe has become marked among both scientists and policy-makers. National governments, the European Commission and even Pope Benedict XVI have highlighted Europe's low level of fertility as a challenge to long-term social and economic sustainability, while demographers have devoted considerable scholarly attention to explaining why the birth rate is so low and what might be done to raise it (McDonald 2002, Demeny 2003, European Commission 2005, Vatican 2006, Vos 2009). Demeny (2003), elaborating on the 2001 global population projections by the United Nations suggested that the marginalisation of European populations within the global population is a "fait accompli" (p. 14) and that "immigration is unlikely to halt the decline of population in Europe" (p. 28). Of concern to many are the official Eurostat population projections which predict that the European Union population will start shrinking in the medium term. ${ }^{1}$ At the same time, researchers have documented huge regional diversity in European fertility, migration and population trends, which became more pronounced after the collapse of state socialism in Central and Eastern Europe between 1989 and 1991 (Sobotka 2008a, Avdeev et al. 2011).

There has also been considerable debate on the role migration can play in compensating for fertility below the replacement level. In 2000, the United Nations report Replacement migration: Is it a solution to declining and ageing population? triggered extensive (and very diverse) media

\footnotetext{
${ }^{1}$ For instance, the baseline scenario of Eurostat population projection issued in 2005 envisioned that the EU population would start shrinking in 2025 (Eurostat 2005 and 2006; with no migration, the EU population was projected to start shrinking as early as 2008). Two years later, the projected starting year of the EU population decline was put off to 2036 (Eurostat 2008), whereas the latest set of projections, released in 2011, expect the EU population to peak around 2040 (Eurostat 2011a).
} 
comment on the matter (Tarmann 2000), with many of the official government responses being unusually sharp (Teitelbaum 2004). These views were often in line with some earlier studies suggesting that large-scale immigration is not politically viable in Europe (Teitelbaum and Winter 1985). However, since the media frenzy set off by the United Nations, migration has gradually become recognised as an important structural feature of European societies, especially since many parts of Southern, Western and Northern Europe experienced considerable population increase in the first decade of the $21^{\text {st }}$ century, largely fuelled by increasing migration (and to a smaller extent by rising fertility rates) (Avdeev et al. 2011, VID 2012). Coleman (2006) argued that substantial immigration to rich countries will lead to irreversible transformation of their population composition, constituting a "third demographic transition." In this context, an interesting question was whether any European countries had already experienced migration levels that could be seen as constituting 'replacement migration' (e.g., Lesthaeghe 2000, Alho 2008, Bijak et al. 2008, Billari and Dalla Zuanna 2011). Although some evidence suggests this has been the case in many countries, no clear definition of replacement migration exists, making the debate on this subject inconsistent. As Beaujot (2003: 1) noted, "the idea of using immigration to "keep the population the way it was" can be used not only with regard to maintaining a certain growth rate, or avoiding decline, or preventing ageing, but also with regard to regional distribution, even ethnic or linguistic distribution, or socioeconomic composition" (see Ryder 1997, Lesthaeghe 2000, Coleman 2001, Espenshade 2001, Keely 2001, Beaujot 2003, and Saczuk 2003 for a critical assessment of the concept).

One possible conceptualisation of replacement migration assesses whether immigrants can boost the observed number of births in a country so that they close the gap between the observed number of births and a hypothetical number of births that would correspond to replacement fertility. This approach can be termed birth replacement migration. Another concept of replacement migration, termed population replacement migration, asks whether immigration can inflate the population size in a real or synthetic cohort as it ages, so that it eventually makes up for the difference between the observed number of births and the hypothetical number of births that would have been achieved if fertility reached replacement level. A long-term combination of sub-replacement fertility and replacement migration could eventually lead to a stationary population, i.e., a population with constant size and fixed age structure (under the assumption that 
mortality rates also remain constant; see Espenshade 1982 and Alho 2008). Succinct examples of such a process taking place over many decades in Northern Italy can be found in Dalla Zuanna (2006). Our contribution to this debate builds on earlier research (see especially Sobotka 2008a, Dalla Zuanna 2008) and makes use of a cohort indicator of population replacement, the Overall Replacement Ratio (ORR), which tracks changes in the size of a birth cohort relative to the size of the cohort of its mothers. We concentrate on cohort trends in the ORR of women from the time of birth up to their peak reproductive age (defined here as age 30) and contrast this measure with selected other existing measures of population replacement. The ORR is a simple measure which performs well compared to these more complicated measures and it clearly indicates that many European countries are indeed experiencing population replacement migration.

\section{Measurement}

As many rich countries experienced high immigration rates, increasingly affecting childbearing (Sobotka 2008b) as well as population trends (Eurostat 2011b, Sobotka 2009, Coleman 2006), the need to rethink the traditional indicators of population replacement has become obvious (Calot and Sardon 2001; Smallwood and Chamberlain 2005). Already in 1997, Ryder's study on Canada has posited that, in the context of persistent sub-replacement fertility, combined with significant immigration, the conventional model of a stable population closed to migration no longer corresponded to the actual experience. Later, a new strand of research aiming to assess the combined effects of fertility and migration (and, more conventionally, often accounting for mortality) on population prospects has sprung into life.

Despite the recognition that replacement migration is an important issue no measure has yet become a de facto standard. Two broad factors may explain this. First, as mentioned above, it is not self-evident which populations or population characteristics are to be 'replaced' or 'maintained' with migration. Research to date has shown that migration cannot strongly alter, let alone stop, the process of population ageing in the most developed countries, as measured by oldage dependency ratios and other indicators (UN 2000, Lesthaeghe 2000, Bijak et al. 2007). ${ }^{2}$ Even

\footnotetext{
2 However, Alho's (2008: 649) study suggests that in populations that can accommodate increasing net migration, this increase can "markedly slow down the aging of a population." Earlier simulations of Coale (1986) of the effect of immigration on the size and age structure of the US population showed that immigration can alter population's age composition especially in those with low or very low fertility rates. For instance, simulating US population up to
} 
so, migration has been repeatedly shown to have a potentially important role in maintaining the size of working-age population, adding to the number of births in a country, or expanding the size of initially small birth cohorts born during low fertility periods (Ryder 1997, UN 2000, Lesthaeghe 2000, Daguet 2002, Dalla Zuanna 2006, Preston and Wang 2007, Ediev et al. 2007, Alho 2008, del Rey Poveda and Cebrán-Villar 2010, Billari and Dalla Zuanna 2011). Second, migration is the most unstable and unpredictable component of population change. Due to this instability, it is problematic to use migration rates for any particular year to estimate period indicators of long-term population replacement. In order to avoid this volatility, we use a measure that shows the cumulated impact of migration on birth cohort size, rather than conventional period rates. The measure we propose and the data used to estimate it are discussed in the next sections.

As with any standard demographic indicators, measures of birth and population replacement can be computed on a period or a cohort basis (Calot and Sardon 2001) or they can combine both approaches, as a growing number of studies on replacement migration show. More attention has been paid to the indicators of birth replacement, analysing the actual or hypothetical population reproduction in the presence of migration. Period indicators of birth replacement date back to the work of Hyrenius (1951), who suggested a Social Replacement Rate (S), including migration, as a counterpart of the conventional Net Reproduction Rate (NRR). More recent period measures of birth replacement include the Net Reproduction Rate in the presence of migration (NRR*) by Preston and Wang (2007) and the Combined Reproduction (CR) by Ediev et al. (2007, 2012). The latter indicator also aims to account for the higher fertility level of immigrant women. ${ }^{3}$. Period indices of birth replacement do not have to be hypothetical synthetic indicators: they can also relate the size of "children's generation" as captured by the number of female live births in year $t$ to the mean size of the mother's generation at birth, as in the case of the Birth Replacement Ratio (BRR) proposed by Ortega and del Rey Poveda (2007; see also del Rey Poveda and

\footnotetext{
2100 assuming different levels of fertility and two scenarios of migration (no immigration vs. net immigration of 700,000 per year) showed that adding immigrants to the population with a period TFR of 1.4 changed the ultimate proportion aged 65+ in 2100 so that it corresponded to the population with a TFR of 1.6 and no immigration (Coale 1986: 208, Table 2). A recent debate on the subject in Genus, informed especially by fertility, mortality and migration patterns in the low-fertility setting of Italy tended to differentiate between short-term effects, where migration can alter the trajectory of population ageing, and long-term effects, where migration has little influence (de Santis 2011, Gesano and Strozza 2011).

${ }^{3}$ The authors assume in their comparative study that migrants' period total fertility rate exceeds by $25 \%$ that of the 'native' women.
} 
Cebrán-Villar 2010). Cohort measures of birth replacement can also be derived (e.g, Hyrenius 1951, Calot and Sardon 2001).

In contrast to the indicators of birth replacement, measures of population replacement do not pertain to biological reproduction. Rather, migration is seen as a 'substitute' for low levels of biological reproduction and the main question is how immigration modifies the size of different birth cohorts either before they reach their prime reproductive (or productive) age or throughout their entire life span. The key difference between the indicators of birth replacement and population replacement can be illustrated with a hypothetical example of a population with zero fertility and massive immigration. In this population, birth replacement would be zero, but population replacement can be relatively high and corresponding to a stationary population: by reaching a certain age, the population would completely 'replace' itself through migration alone.

Indicators of population replacement can also be computed from either a period or a cohort perspective. A purely period-based indicator of population change through migration across entire life span has been proposed by Ediev et al. $(2007,2012)$ and termed Completed Net Migration (CNM). ${ }^{4}$ A cohort-based approach, comparing the size of a 'children's cohort' as it ages to the (fixed) size of their mother's cohort at the time they were born has been proposed and discussed by Dalla Zuanna (2008; see also Billari and Dalla Zuanna 2011) and Sobotka (2008a). Dalla Zuanna's Index of Replacement Including Migration, RM, compares the size of two generations (mother's cohort and children's cohort) at the same age, while Sobotka's (2008a) Gross Replacement Rate (GRE) combines period estimates of biological reproduction (the gross reproduction rate in the year of cohort's birth) with the data on subsequent changes in cohort's population size to estimate replacement for each cohort. ${ }^{5}$

\footnotetext{
${ }^{4}$ Alho (2008: Figure 2) computed ratios of net migration to births and showed different combinations of female total fertility rate and net migration needed to maintain stationary population in four Nordic countries. Different age patterns of fertility and age distribution of net migrants imply that these 'tradeoff values' are country-specific.

${ }^{5}$ In addition to indicators of population replacement, other measures, including both projections and simulations have been used to estimate the impact of migration on the population. Traditionally, much discussion focused on a stable population model and on identifying a constant stream of immigrants needed to achieve stable population in the long term, given observed or projected sub-replacement fertility rates (e.g., Coale 1986). Coleman (2009) related period numbers of net migrants to the total number of live births, showing that a number of European countries had net migration exceeding 50\% of live births around 2008 (see also Alho 2008). In their projection scenarios for the EU-15 countries (EU members as of 2003), Lutz and Scherbov (2003: 11-12) proposed that "the effect of 100,000 additional immigrants per year corresponds to that of an increase in the TFR of 0.1."
} 
In this study we focus on population replacement. We present a very simple method to assess how far migration alters the extent of replacement for a birth cohort as it ages. In order to avoid problems associated with the estimation of fertility, mortality, and migration, we ignore the vital processes altogether, and provide a direct comparison of the size of age groups. We term the measure used here the Overall Replacement Ratio (ORR). It is calculated by taking the size of a female birth cohort ${ }^{6}$ divided by the estimated average size of the cohort of mothers in the year of birth. We use female cohorts to facilitate comparison with conventional fertility indices, but male cohorts (or the two sexes combined) could be equally well studied in this way. In its interpretation, computation and aim, the ORR is very close to the RM proposed by Dalla Zuanna in 2008 and to the GRE proposed by Sobotka (2008a). Direct comparison of the GRE and ORR shows that we mostly achieve identical results using the more simply defined ORR (Wilson et al. 2010, see also below). We prefer to use the ORR because it requires information solely on age structure, whereas the GRE uses the total fertility rate, or gross reproduction rate, as well as age structure. Although this measurement simplification is not a large advantage for contemporary European populations, for historical data and some developing countries where age structure is known but age-specific fertility is not, the ORR could have significant advantages. The simplicity of the data required for the ORR also means that it can be calculated for any population for which repeated age-specific estimates of its size are available. This means it can be calculated for small areas or sub-populations defined by socio-economic, ethnic or other characteristics. However, when the age structure of women in the reproductive ages is changing rapidly, the GRE may provide more stable estimates

The $O R R$ is derived in this study as follows:

Let $F(a, c, t=c+a)$ be the size of the female cohort aged $a$ and born in year $c$ (observed in the year $c+a$ ). This cohort, termed also "daughters' cohort," is made up of women residing in the country by age $a$ and includes those immigrating before reaching age $a$. The mothers of these women ("mothers' cohorts") were born over an interval roughly centred at year $c$-g, where $g$ represents

\footnotetext{
${ }^{6}$ Note that in our approach, birth cohort is defined solely by the same year of birth and the same country of residence at age $x$ for which the ORR is computed. Thus, our birth cohort is composed of 'native' women as well as immigrants, potentially from many different countries, arriving to the country of interest before reaching age $x$.
} 
mean generational interval, which can be approximated by the cohort's mean age at childbearing. We denote the lower and upper bounds of the prime childbearing ages of these mothers' cohorts in year $c$ by $\mathrm{x}=\left(m_{1}, m_{2}\right)$, and the age-range from $m_{1}$ to $m_{2}$ as $n$. Then the average size of the mothers' cohorts (born across the years c-x and observed in year $\mathrm{t}=\mathrm{c}$ ) contributing to birth cohort $c$ can be written as:

$$
\sum_{x=m_{1}}^{m_{2}} F(x, c-x, t=c) / n ; \mathrm{n}=\mathrm{m}_{2}-\mathrm{m}_{1}+1 .
$$

We define the ORR for cohort $c$ at age $a$ by:

$\operatorname{ORR}(a, c)=F(a, c+a, t=c+a) / \sum_{x=m_{1}}^{m_{2}} F(x, c-x, t=c) / n$.

The delineation of the "mothers' cohorts" and of their 'daughter's cohort" used in the ORR computation is illustrated in a Lexis diagram (Figure 1). Note that the size of the mothers' cohorts is 'frozen' in year c, i.e., at the time of their daughters' birth, while the size of the daughter's cohort changes, depending on age a for which the ORR is derived. An ORR of 1 would indicate exact cohort replacement, whether through birth or subsequent migration, by the specified age a. ${ }^{7}$

\section{Figure 1 about here}

In this paper we take ages 20 and 35 for $\mathrm{m}_{1}$ and $\mathrm{m}_{2}$, indicating roughly the limits of the main childbearing ages in most countries during the 1970s and 1980s, the birth cohorts which we are mostly studying here. ${ }^{8}$ Other age ranges and more complex definitions of the average size of the mothers' cohorts could, of course, be taken, but our initial analysis suggests that for the European countries studied here 20-35 is the most suitable choice (see Appendix 1). With some exceptions, the ORR does not seem to be strongly affected by the definition of the mothers' cohorts, as long

\footnotetext{
${ }^{7}$ It is not the extent of immigration as such, but the net balance between immigration and emigration, which determines the ORR computation.

${ }^{8}$ We use the female population distribution by age on January 1 of two subsequent years, $t$ and $t+1$, to estimate mean female population in the "mothers' cohorts" in the year $\mathrm{t}=\mathrm{c}$.
} 
as the range selected is large enough to wash out effects of short-term baby booms and busts. ${ }^{9}$ In historical populations and for European populations in more recent years (when fertility has been significantly delayed compared with the 1970s and 1980s), a broader age range (e.g. 20-40 or 2044) appears more suitable (Appendix 1). When calculating the ORR for populations in which there are significant perturbations in the age structure (for example, countries such as China or Iran, where fertility decline has been especially rapid), more precise definitions of the mothers' cohorts would be advisable. For present purposes, however, we have chosen to keep the definition as simple as possible. Because our main interest lies in tracking how the generation of mothers with below-replacement fertility is subsequently 'replaced' by a positive migration balance, we focus on tracking the ORR until the ages when their daughters typically become mothers themselves. At these ages, cohort survivorship in contemporary developed countries is practically unaffected by mortality, which makes the ORR changes over time almost entirely determined by fertility and subsequent migration.

\section{Using the ORR: Data, illustrations and interpretation}

The principal data we use in this paper for calculating the ORR are taken from Eurostat's online database. For Ireland we complement the Eurostat data with the estimates of female population by age from the Human Mortality Database (HMD 2012), while historical data for Sweden are derived from both the Human Fertility Database (2011 and 2012) and the HMD (2012). The national statistical offices of all the member states of the European Union make annual estimates of their populations by single year of age. These are then collated by Eurostat and made available (along with data for selected other European countries) on their website (Eurostat 2012). It is important to realize that these data often constitute estimates that differ from the 'true' population size. Countries calculate the population resident in their territory in different ways; someespecially the Nordic countries, but also Austria, Estonia, the Netherlands and Slovenia-can make use of detailed and accurate population registers, while others have to rely on combinations of vital statistics and decennial censuses, which themselves may be deficient in various ways.

\footnotetext{
${ }^{9}$ The ORR can show notable differences from indicators that define the size of the "cohort of mothers" more precisely in the following cases: 1) when the selected lower and upper boundaries of prime reproductive ages do not match well the actual boundaries; 2) when childbearing is strongly concentrated into a narrow age band, and 3) when the size of the analysed cohorts changes abruptly. For instance, a combination of the second and the third factor led to a wide divergence between the ORR and more precisely defined indicator (the 'traditional' gross reproduction rate, GRR) in the case of the late 1960s and the 1970s cohorts in Slovakia (not shown here, data available upon request).
} 
Thus, the data we are using constitute the "best guesses" of Europe's national statistical offices, which can be affected by different definitions of resident population and by different degrees of accuracy in registering immigration and emigration. While some statistical offices are at pains to point out the approximate nature of their population estimates, it is evident that these "best guesses" mostly provide highly plausible and consistent information on the evolving population structures of the EU's member states. The greatest concern over the robustness of the estimates is for some countries in Eastern Europe that have seen large-scale emigration since 1989 and where the infrastructure of national statistics is weaker than elsewhere in the EU. In such cases, data may be missing for certain years or sharp discontinuities may be evident in the data series. Overall, however, in most cases the Eurostat data clearly capture the main trends in each country.

Using these data, we now give some simple empirical illustrations to show the merits and limitations of the ORR. For example, we can compare the size of the 1980 cohort over time to the number of women in the main childbearing ages in 1980. Using annual estimates of the size of the 1980 cohort enables us to track the impact of migration on its implied level of replacement. In the absence of migration, this ratio will remain almost constant for the first decades of life, corresponding roughly to the net reproduction rate of the year 1980 and then decline as mortality reduces the size of the cohort. However, where there is significant net immigration, the ratio will rise as the cohort ages, with the increases taking place at the ages of immigration. Conversely, with net emigration, the ratio will decline as the cohort ages.

Given that most migrants move at young adult ages, immigration leads to additions to the size of a birth cohort especially between ages of 15 and 40. This age profile of migration can strongly modify the size of each cohort before it reaches typical childbearing ages. For example, it is possible for every cohort to reach the replacement level, while some widely used age structure indicators, such as the conventional age pyramid, show a striking shortfall in the relative size of the cohort throughout childhood.

Figure 2 about here 
As an illustration, Figure 2 presents estimates of the ORR for selected female birth cohorts in Austria from 1970 to 1995 . The ratios are based on annual single-year of age population estimates from 1969 to 2011 provided in Eurostat (2012). The uppermost line (1970 birth cohort) starts above 1 (the replacement-level) and remains there, expanding further throughout the next 30 years. The year 1972 was the last in which the period total fertility rate in Austria exceeded the replacement level and all later cohorts begin below 1 . The cohorts show varying, though modest, changes for the first 10-15 years of life, but all rise substantially from the late teens on, when significant net immigration begins to increase the cohort sizes. The experience of each cohort is truncated at its age in 2011 , but it is clear that all the cohorts that have reached age 30 passed the population replacement level before attaining that age, and the subsequent cohorts are likely to do so in due course.

To illustrate the differences between the overall replacement ratio and other indicators of reproduction and replacement we compare its trends in Sweden in the cohorts of women born in 1950-1980 with the conventional period net reproduction rate (NRR), the NRR in the presence of migration (NRR*, Preston and Wang 2007) and with the net birth replacement ratio, NBRR (del Rey Poveda and Cebrán-Villar 2010). ${ }^{10}$ In Table 1 and Figure 3 we highlight the contrasts in the underlying assumptions as well as in empirical results provided by these measures. The NRR, which measures biological reproduction in a single-year synthetic cohort framework, fell below the replacement threshold in 1968 and with a brief exception of 1991-92 stayed below that level, fluctuating widely in line with the ups and downs of period fertility in Sweden (see Oláh and Bernhardt 2008). The NRR* captures in addition the influence of migration on the hypothetical birth replacement rate in a comparable synthetic cohort framework, based on the observed fertility and net migration rates in a single year. As migration also fluctuated widely, the migration-adjusted NRR* shows even less stability than the NRR, reaching a minimum of 0.79 in 1983 and recently peaking at a high level of 1.35 in 2009. Similar trends, but considerably more stable results are depicted with the NBRR, which is an indicator of birth replacement relating the observed number of births ("cohort of daughters") in a year to the size of the "cohort of mothers" at birth. This is a quasi-period indicator, which—similar to the NRR and NRR*-measures

\footnotetext{
${ }^{10}$ For the NBRR computations we used equations 6, 7 and 8 in del Rey Poveda and Cebrán-Villar (2010); for the NRR* we have followed life table computations described in Appendix 1 in Preston and Wang (2007), adapted to a single-year framework (the authors based their computations on 5-year periods).
} 
period birth replacement in a given year, but which is, in addition, affected by the migration history of all the cohorts of mothers of reproductive ages prior to that year. During the analysed period, the NBRR follows relatively closely the NRR trends until 1970, indicating that migration to Sweden had little impact on the observed number of births in 1950-70 (however, a crossover is observed in 1956, with migration shifting from having a negative influence of the observed number of live births to having a net positive effect on total live births). After 1970 immigration became an important factor contributing to the observed number of births in Sweden through both the 'inflated' size of the 'mothers' cohorts' and the higher fertility rates among migrant women (Sobotka 2008b). The NBRR has consequently risen well above the NRR levels, especially since 2004 when the difference between these two indexes has exceeded 0.1 in absolute terms. In the long-term, the NRR suggests that biological reproduction among Swedish women fell short of replacement level by $14 \%$ in 1968-2010 (average NRR $=0.86$ ), while the two indicators of birth replacement suggest close-to-replacement number of births in Sweden (average $\mathrm{NRR}^{*}=1.01$, average $\mathrm{NBRR}=0.96$ ). The contrast between these three measures was particularly strong in the most recent period, when the NBRR and even more so the NRR*, indicated high birth replacement rates, implying increasing cohort size at birth.

Finally, the ORR is a cohort indicator that combines biological reproduction in a cohorts' birth year (comparable to the period for which the NRR, NRR* and NBRR were computed) with subsequent net migration that inflates or decreases the cohort size. Because fertility in the year of the cohort's birth usually affects the ORR more than subsequent migration, we compare the ORR(30) with the period-based indicators of birth replacement and reproduction in the year of cohorts' birth, rather than shifting it by a time lag corresponding to the age for which the ORR is computed. Among the cohorts born in 1970-79 the ORR at age 30 stood well above the corresponding levels of biological reproduction and birth replacement. In 1978, when the NRR reached a low of 0.77 , the two birth replacement indicators also reached relatively low levels of $0.83(\mathrm{NBRR})$ and $0.85\left(\mathrm{NRR}^{*}\right)$, respectively, while the ORR reached 0.94 , indicating that by age 30 migration has increased the size of the 1978 cohort of women almost to the size of their mothers' cohorts in 1978. The observed trends suggest that the ORR at age 30 in Sweden reached its lowest post-war level in that year and it is likely to remain above population replacement for 
the cohorts born since 1981. As we shall illustrate in our analysis, this pattern of migration acting as population replacement is not unique to Sweden.

\section{Table 1 about here}

Figure 3 about here

\section{Results}

Figure 4 gives the ORR by age for the EU-15 (i.e. the old EU before the enlargements of 2004 and 2007), while Figure 5 presents the same information for twelve European countries. The birth cohorts chosen range from 1972 to 1995 and the cohorts' experience is truncated at ages between 18 and 35, with the most recent data pertaining to January 1, 2011. We selected these cohorts because the conventional indicator of fertility, the Total Fertility Rate (TFR) first fell below the replacement level for the EU-15 in the 1974 cohort. Since much migration only happens from the late teens onwards, cohorts born after 1990 have generally not yet had sufficient time to see significant immigration.

\section{Figure 4 about here}

The results for the EU-15 in Figure 4 paint a clear and consistent picture. The initial values of the ORR fall steadily over time, as this was a period of rapidly falling fertility, especially in Southern Europe. However, there is a strong upward trend in the ORR as each cohort ages. The 1980 cohort was born with a size about $12 \%$ below the average of its" "maternal cohort" (ORR of 0.88 ) However, by the time the cohort reached age 30 , its size had expanded so as to surpass by $4 \%$ the size of its "maternal cohort" in 1980. Younger cohorts were born with progressively lower relative size and are unlikely to surpass intergenerational replacement until later in life, but are, nevertheless, clearly moving close to that level. A similar pattern is reflected, with variations, in the graphs in Figure 5 for Belgium, France, Germany, Italy, Sweden, and Switzerland, and the United Kingdom. The lines all begin well below one, sometimes far below (e.g., Switzerland), indicating that fertility was below the replacement level. As each cohort ages, it usually increases in size, although a few downward movements are also recorded. The ages and cohorts at which the largest rises occur also vary, and the impact of specific migration events can be seen. For 
example, the large rise in each cohort in Germany in the early 1990s indicates the influx of refugees from the former Yugoslavia. Whatever the specific national features, the broad similarity of graphs for Western European countries is apparent. The panel for Switzerland shows, perhaps, the most striking and stable pattern of immigration systematically compensating for the shortfall of births, the result of sustained high immigration for several decades. In contrast, in Germany very low fertility, together with less intensive migration, implied an ORR that remained consistently below one in all the cohorts observed.

\section{Figure 5 about here}

The results for Spain show a different pattern; they are also shown on a different scale from the other countries because Spanish fertility remained higher longer, with the ORR at age zero not falling below one until the 1982 cohort. The dramatic upsurge of immigration into Spain over the last two decades (prior to the onset of the recent recession) is also readily seen in the lines plotted. In Spain immigration seems to have more than filled the gap in cohort sizes created by very low fertility. To some extent the precise track of the Spanish curves may be deemed somewhat conjectural, as much of the immigration into Spain has been initially undocumented, and only later regularized in a series of amnesties. Nevertheless, there is no ambiguity about the scale of replacement migration in Spain. No other country of Europe has seen a similar extent of immigration, with 5.2 million people added to the Spanish population of 40 million during the first decade of the millennium (Sobotka 2009). With its distinctive combination of very low fertility and massive immigration, Spain is an intriguing example of a country where the ORRs ultimately jump well above replacement and imply rapid population growth.

The next two panels in Figure 5 show the Czech Republic and Hungary. Here we see a very different pattern. Until the end of Communism in 1989 international migration was negligible and so the lines for each birth cohort run horizontally, with just a few minor discontinuities, possibly corresponding to mismatches between earlier estimates and updates following censuses. But, as in the older member states, immigration is coming to play a significant role more recently. In the Czech Republic, from about the time of accession to the EU in 2004, the lines curve upwards. The Hungarian results show yet another pattern. Clear discontinuities are evident around the time 
of the collapse of Communism, and thereafter younger cohorts show a gradual increase in the ORR. The increase is mostly a reflection of migration to Hungary of ethnic Hungarians from neighbouring countries, especially Romania.

Finally, last two panels reflect countries in South-eastern and Eastern Europe which have experienced substantial emigration, which is often poorly documented. Therefore, the official data frequently display peculiar and unlikely jumps and breaks. Nevertheless, the graphs for Bulgaria and Latvia paint a clear picture of populations that are rapidly shrinking, with subsequent cohorts displaying ever lower initial ORRs at birth (especially in Bulgaria) and then shrinking yet further as emigration depletes the resident population at younger ages. The most spectacular emigration effect is observed for the 1975 cohort in Bulgaria which had an ORR well above replacement at the time of birth (1.17), but had contracted by almost a quarter, reaching an ORR just above 0.9 by the time it reached the age of 35 .

\section{Regional comparison}

- To provide a more systematic assessment of population replacement in different parts of Europe, Table 2 gives the overall replacement ratio at ages 0 and 30 for two cohorts of women born during a period of declining fertility, 1975 to 1980. Country data are grouped by broader regions. The declining fertility of the late 1970s is clearly reflected in the fall or a stagnation of the ORR at age 0 between the two cohorts (Germany, where fertility fell strongly before 1975, is an exception). However, the trend at age 30 is much less clear-cut, with Austria, Belgium, Germany, Ireland, Sweden, Switzerland and the United Kingdom all seeing increases in the ORR(30) between the 1975 and 1980 cohorts. High fertility in 1980 combined with subsequent immigration pushed the $\operatorname{ORR}(30)$ in Ireland as high as 1.75. Almost everywhere in Europe (the only exceptions were Ireland and some Southern and Eastern European countries), the 1980 cohort was initially 'endowed' with sub-replacement level. By the time this cohort reached age 30 , however, the ORR was close to or above the replacement level in most cases and above 0.9 almost everywhere (except in Denmark and parts of post-communist Europe). As a further rise in the ORR is likely to occur after age 30, it seems safe to conclude that in most countries the 1980

cohort will probably surpass the value of 1 before its members reach age 40. Only in a number of ex-communist countries has the ORR actually declined, though in a few cases, including 
Bulgaria, Latvia and Romania, it has plummeted, a trend that is likely to have long-term negative consequences for the population structure. These countries face the challenging prospect of sizeable and lasting population decline, especially if emigration continues among the younger cohorts born in the period of extreme low fertility in the late 1990s and early 2000s.

- Almost all the countries analysed saw a larger increase in the ORR for the 1980 cohort than for the 1975 cohort. The absolute and relative increases in the ORR between ages 0 and 30 were particularly marked in Ireland, Spain and Switzerland, with absolute increases of 0.27-0.38 in the 1980 cohort. In short, even countries with very low fertility and net reproduction rates around 0.7 (i.e., with the TFR below 1.5) can reach replacement migration as early as at age 30. Hungary and the Czech Republic made a transition from a declining ORR with age to an increasing one between the 1975 and 1980 cohorts, possibly following an earlier pattern of Southern Europe.

\section{Table 2 about here}

The scatterplot in Figure 6 adds a further dimension to this comparison. Though almost all the countries have moved to a below-replacement ORR at age 0 (ORR on the $x$ axis lower than 1), this is not necessarily so by age 30. It also shows that the EU-15 reaches an ORR around 1 by age 30. It further indicates that the ORR rises with age in all non-Eastern European countries (i.e., the points in Figure 6 are clustered above the diagonal). And, finally, it reveals that the initially rather close correlation between the ORR at age 0 and at age 30, as depicted for the 1975 cohort, does not hold much for the 1980 cohort, especially if Ireland and Spain, the prominent outliers to the upper right of the graph, are disregarded.

Figure 6 about here 


\section{Conclusions and implications}

Six decades ago Hyrenius (1951) made a key distinction between biological reproduction and 'social replacement.' Since then dozens of studies have debated whether migration can partly or fully compensate for a perceived 'shortage of births' and population imbalances, especially in rich countries and regions. Many of these studies focused especially on the levels and patterns of migration needed to achieve a 'stable population', given observed or hypothetical levels of fertility and mortality. With relatively high immigration seen in the last two decades (especially prior to 2009) across most of the developed world the concept of replacement migration has increasingly entered into the debate. This interest in the long-term effects of migration has been, however, hindered by imprecise and deficient data on migration flows as well as the lack of widely shared standard measures and indicators.

Our study highlights three important points. First, we emphasise the distinction between birth replacement effects of migration (i.e., migrants contributing to hypothetical or observed number of births) and population replacement impacts of migration (i.e., migrants 'filling the gap' in population size attributable to sub-replacement fertility). Second, we contribute to the growing array of measures of birth and population replacement and propose a simple indicator of cohort population replacement. Third, our new indicator, which has been developed in parallel with a similar index by Dalla Zuanna (2008), throws a clear light on the nature of population dynamics in many parts of Europe, suggesting strongly that some of the past projections of Europe's imminent demographic demise are far from realistic. In much of Europe it is manifestly clear that, while the idea of replacement migration, as proposed by the United Nations in 2000, was widely criticized, in reality this is precisely what is happening.

Given that demographic processes are inherently unstable, and thus that the stable population concept remains a theory unmatched by long-term historical experience, it is surprising to observe that in many European countries cohorts of women born in the period of sub-replacement fertility actually achieved the size corresponding to population replacement level by the time they reached their prime reproductive (and productive) ages. Using a different method, Alho (2008: 644) showed that low fertility in Europe is "associated with high net migration and vice versa," implying that migration has reduced dispersion in intrinsic rates of population growth across 
Europe. Similarly, Billari and Dalla Zuanna (2011: Figure 2) demonstrated that migration rates in Europe are strongly and inversely correlated with the dynamics of births. However, these observations need to be put into broader context. Frequently, the impact of migration goes well beyond a small 'topping up' of population numbers and a few countries obviously 'over-achieve' in this regard and see significant population growth as a result of immigration (e.g. Ireland, Spain, and Switzerland). In contrast, since the 1990s some of the economically struggling countries of Eastern and South-eastern Europe, often ignored in comparative European analyses, have shown the doubly negative effect of low fertility and large-scale emigration, implying a prospect of significant population decline.

Countries such as Spain or Switzerland show that even very low levels of fertility rates can be combined with replacement or above-replacement levels of migration. The richer countries among those that joined the EU in 2004 (e.g., the Czech Republic and Slovenia) are showing clear signs in the same direction. There are, of course, exceptions from this general trend and many region-specific patterns. Some affluent countries, including Germany and the Netherlands, have experienced short periods of net emigration in the past and the recent economic recession has resulted in net emigration in yet more countries for some years to come. The less wealthy EU member states, especially the Baltic countries, Bulgaria, and Romania, in common with most of Eastern Europe beyond the EU boundaries, are still experiencing substantial emigration. However, taking a longer time perspective, the waves of emigrants from countries such as Poland or Romania today have a parallel in mass emigration from Portugal, Spain and Italy from the 1950s to the 1970s. All three of these Southern European countries have since switched to becoming large net 'importers' of people. If their experience is a valid guide, the countries that joined the EU in 2004 and 2007 can expect similar reversals in due course, and the establishment of large-scale replacement migration.

By itself, replacement migration is not a remedy to Europe's problems with an ageing population, but rather it can be seen as a potential opportunity that should be complemented with policies that aim to enhance socio-economic sustainability, including: supporting the integration of migrants; increasing the labour market participation of women; delaying retirement; and further increases in higher education attainment for both native and migrant populations. Some immigration-averse 
governments may aim to stimulate fertility while reducing migration. But earlier European experience suggests that both pronatalist and anti-immigration policies often fail to achieve the desired goal and have unintended adverse consequences (Castles 2004, Gauthier 2007).

The measure proposed here, the overall replacement ratio, is a simple, easily calculated index; it can readily be compared over time and across countries-even in settings with rather rudimentary population estimates and vital statistics - and is intuitively understandable. By focusing on changing relative cohort size, the ORR shows much higher stability than the synthetic indicators of birth and population replacement constructed from period-based data only. When computed for single years, these indicators_-including the indices proposed by Ediev et al (2007 and 2012) and by Preston and Wang (2007)—are affected by both year-to-year instability and incomplete statistics on migration. In the long term, however, the errors in the statistics on migration and population data are likely to smooth out, making ORR a suitable indicator of population replacement. Low data requirements make it ideal for analysing population replacement in both contemporary and historical populations, but also for looking at population dynamics at subnational level, where internal migration often plays more important role than international migration streams (see Wilson and Williamson 2011 for the UK, del Rey Poveda and CebránVillar 2010 for selected Spanish regions, Billari and Dalla Zuanna 2011 and Dalla Zuanna 2008 for Italian regions), or in poorer countries where data limitations may be more substantial. In addition, the ORR can be assessed at different ages, making it able to respond flexibly to the analyst's needs. While we have chosen to focus on age 30 as a mid-point of reproductive span, the ORR can also track changes in relative cohort size across productive ages when migrants contribute to the labour force or be employed to analyse shifts in relative population size before reaching retirement.

Appendix 1, which compares the ORR at ages 0 and 30 with the conventional gross and net reproduction rates for Sweden over the long-run suggests that the ORR may also make a reasonable proxy for these conventional indicators when detailed information on fertility and mortality is lacking. In spite of its simplicity, the ORR usually performs as well as more sophisticated cohort replacement measures and is, under normal circumstances, relatively insensitive to the definition of the mother's cohort. In the absence of large sudden shifts in the 
mothers' cohort size, the error resulting from an estimation of the mother's cohort size, rather than its precise measurement, is likely to be of a considerably smaller magnitude than the errors and definitional problems contained in the official population data for many countries. In sum, the overall replacement ratio does not aim to substitute for any of the existing and more sophisticated measures of population dynamics, but we think it can play a useful role as a simple measure for indicating the combined effects of fertility and migration on inter-generational replacement.

\section{Acknowledgements}

The research for this paper by Wilson, Williamson and Boyle was supported by the ESRC Centre for Population Change. Sobotka's work on the revisions of this paper in 2012 was funded by the European Research Council under the European Union's Seventh Framework Programme (FP7/2007-2013) / ERC Grant agreement $n^{\circ} 284238$. Earlier versions of the paper were presented at the European Population Conference, Vienna, September 2010, and also published as a Working Paper of the ESRC Centre for Population Change (Wilson et al. 2010). We received helpful comments on earlier versions from Máire Ní Bhrolcháin, Gianpiero Dalla Zuanna, Josh Goldstein, Elspeth Graham, participants at the 2010 European Population Conference and three anonymous reviewers. We also wish to thank Kryštof Zeman for providing us his computations of selected indicators for Sweden, used in Figure 2 and Dalkhat Ediev for sharing with us his unpublished manuscript on population reproduction (Ediev et al. 2012). 


\section{References}

Alho, Juha M. 2008. "Migration, fertility, and aging in stable populatuions.” Demography 45(3): 641-650.

Avdeev, Alexandre, Tatiana Eremenko, Patrick Festy, Joëlle Gaymu, Nathalie le Bouteillec, and Sabine Springer. 2011. "Populations and demographic trends of European countries, 1980-2010." Population-E 66(1): 9-130.

Beaujot, Roderic P. 2003. "Effect of immigration on the Canadian population: Replacement migration?" Discussion Paper No. 03-03, Population Studies Centre, University of Western Ontario, London.

Accessed at: http://www.ssc.uwo.ca/sociology/popstudies/dp/dp03-03.pdf

Bijak, Jakub, Dorota Kupiszewska, Marek Kupiszewski, Katarzyna Saczuk and Anna Kicinger. 2007. "Population and labour force projections for 27 countries, 2002-2052: impact of international migration on population ageing." European Journal of Population 23(1): 1-31.

Billari, Francesco C. and Gianpiero Dalla-Zuanna. 2011. "Is replacement migration actually taking place in low-fertility countries?" Genus 67(3): 105-123.

Calot, Gérard and Jean-Paul. Sardon. 2001. "Fécondité, reproduction et remplacement." Population 56(3): 337-396.

Castles, Stephen. 2004. "Why migration policies fail.” Ethnic and Racial Studies 27(2): 205-227.

Coale, Ansley J. 1986. "Demographic effects of below-replacement fertility and their social implications." In: K. Davis, M. S. Bernstam, and R. Ricardo-Campbell (eds.) Below-replacement Fertility in Industrial Societies: Causes, Consequences, Policies. Supplement to Population and Development Review 12, Population Council, New York, pp. 203-216.

Coleman, David A. 2001. "Replacement migration, or why everyone is going to have to live in Korea: a fable for our times from the United Nations." Philosophical Transactions of the Royal Society B: 357, 583-598.

Coleman, David A. 2006. Immigration and ethnic change in low-fertility countries: A third demographic transition." Population and Development Review 32(3): 401-446.

Coleman, David A. 2009. "Introduction: migration and its consequences in $21^{\text {st }}$ century Europe." Vienna Yearbook of Population Research 2009: 1-18.

Daguet, Fabienne. 2002. "Le remplacement des générations." Chapter 12 in Un Siècle de Fécondité Française: Caractéristiques et Evolution de la Fécondité de 1901 á 1999. Paris: INSEE, 235-252.

Dalla Zuanna, Gianpiero. 2006. "Population replacement, social mobility and development in Italy in the twentieth century." Journal of Modern Italian Studies 11 (2), 188-208.

2008. "La misura RM del rimpiazo delle generazioni”, Populazione e Storia 2008 (2), 61-72. 
Demeny, Paul. 2003. "Population policy dilemmas in Europe at the dawn of the twenty-first century". Population and Development Review 29 (1): 1-28.

De Santis, Gustavo. 2011. "Can immigration solve the aging problem in Italy? Not really..." Genus 57(3): 37-64.

Ediev, Dalkhat, David Coleman, and Sergei Scherbov 2007. "Migration as a factor of population reproduction". Vienna Institute of Demography, European Demographic Research Papers, 2007-1. Available at: http://www.oeaw.ac.at/vid/download/edrp_1_07.pdf

Ediev, Dalkhat, David Coleman, and Sergei Scherbov. 2012. "New measures of population reproduction for an era of high migration" Unpublished manuscript under review.

Espenshade, Thomas J. 1982. "Immigration and the stable population model." Demography 19(1): 125133.

Espenshade, Thomas J. 1986. "Population dynamics with immigration and low fertility." In: K. Davis, M. S. Bernstam, and R. Ricardo-Campbell (eds.) Below-replacement Fertility in Industrial Societies: Causes, Consequences, Policies. Supplement to Population and Development Review 12, Population Council, New York, 248-261

Espenshade, Thomas J. 2001. “"'Replacement migration” from the perspective of equilibrium stationary populations." Population and Environment 22(4): 383-389.

European Commission. 2005. Green Paper. Confronting Demographic Change: a New Solidarity between the Generations. Brussels: Commission of the European Communities.

Eurostat. 2005. "EU25 population rises until 2025, then falls." Eurostat news release 48/2005, 8 April 2005 .

Eurostat. 2006. "Long-term population projections at national level." Statistics in Focus, Population and Social Conditions, 3/2006, Luxembourg: European Communities.

Eurostat. 2008. "Ageing characterises the demographic perspectives of the European societies." Statistics in Focus, Population and Social Conditions, 72/2008, Luxembourg: European Communities.

Eurostat. 20011a. "EU27 population is expected to peak by around 2040." Eurostat news release 80/2011, 8 June 2011.

Eurostat. 20011b. Migrants in Europe, 2011 edition.A statistical portrait of the first and second generation. Eurostat Statistical Books, Luxembourg: Publications Office of the European Union.

Eurostat. 2012. Population on 1. January by age and sex. Datasets accessed at http://epp.eurostat.ec.europa.eu/portal/page/portal/statistics/search_database (accessed 3 May 2012 and previously between December 2009 and August 2010). 
Feld, Serge. 2000. "Active population growth and immigration hypotheses in Western Europe", European Journal of Population, 16(1), 3-40.

Festy, Patrick. 1979. La Fécondité des Pays Occidentaux de 1870 à 1970. Paris: Presses Universitaires de France. Cahier de l'INED, 85.

Gauthier, Anne H. 2007. "The impact of family policies on fertility in industrialized countries: a review of the literature." Population Research and Policy Review 26: 232-346.

Gesano, Giuseppe and Salvatore Strozza. 2011. "Foreign migrations and population aging in Italy." Genus 57(3): 83-104.

Human Fertility Database. 2011. http://www.humanfertility.org. Data on fertility rates in Sweden accessed January 2011.

Human Mortality Database. 2012. http://www.mortality.org. Data on female population in Ireland accessed 3 May 2012.

Human Mortality Database. 2011. http://www.mortality.org. Data on female population and mortality tables by age in Sweden accessed in January 2011.

Keely, Charles. 2001. "Replacement migration. The wave of the future?" International Migration 39(6): 103-110.

Kuczynski, Robert R. 1928. The balance of births and deaths. Volume 1, Western and Northern Europe. The Macmillan Company / The Brookings Institution, New York.

Lesthaeghe, Ron. 2000. "Europe's demographic issues: Fertility, household formation and replacement migration". Paper presented at the conference Population Studies in Britain and in the Netherlands, Utrecht, 2000.

Lutz, Wolfgang and Sergei Scherbov. 2003. "Future demographic change in Europe: The contribution of migration.” Interim Report IR-03-66, International Institute for Applied Systems Analysis, Laxenburg, Austria. Available at: http://www.iiasa.ac.at/Admin/PUB/Documents/IR-03-066.pdf

McDonald, Peter F. 2002. "Sustaining fertility through public policy: The range of options". Population-E 57 (3): 417-446.

Office for National Statistics. 2010. http://www.statistics.gov.uk/statbase/Product.asp?vlnk=15106 Accessed between December 2009 and August 2010.

Ortega, Juan Antonio and Luis Alberto del Rey Poveda. 2007. "Birth replacement ratios in Europe: a new look at period replacement." Paper presented at the 2007 Annual Meeting of the Population Association of America, New York, 29-31 March 2007. 
Philipov, Dimiter and Julia Schuster. 2010. "Effect of migration on population size and age composition in Europe". Vienna Institute of Demography, European Demographic Research Papers, Available at: http://www.oeaw.ac.at/vid/download/edrp_2_10.pdf

Preston, Samuel H. and Haidong Wang. 2007. "Intrinsic growth rates and net reproduction rates in the presence of migration". Population and Development Review, 33(4): 657-666.

Ryder, Norman B. 1997. "Migration and population replacement." Canadian Studies in Population 24(1): $1-26$.

Saczuk, Katarzyna. 2003. "A development and critique of the concept of replacement migration." CEFMR Working Paper 4/2003, Central European Forum for Migration Research, Warsaw. Available at: http://www.cefmr.pan.pl/docs/cefmr_wp_2003-04.pdf

Smallwood Steve and Jessica Chamberlain 2005. "Replacement fertility, what has it been and what does it mean?" Population Trends 119 (Spring 2005): 16-27.

Sobotka, Tomáš. 2008a. "Does persistent low fertility threaten the future of European populations?" in P. Deboosere, J. Surkyn and J. van Bavel and (eds.) Demographic Challenges for the 21st Century. A State of the Art in Demography. Liber Amicorum Ron Lesthaeghe. Brussels: VUB Press, pp. 27-89.

Sobotka, Tomáš. 2008b. "The rising importance of migrants for childbearing in Europe." Demographic Research, Special Collection 7, Vol. 19 (Article 9): 225-248.

2009. "Migration continent Europe", Vienna Yearbook of Population Research 2009: 217-233.

Tarmann, Allison. 2000. "The flap over replacement migration.” Text available at the PRB site: http://www.prb.org/Articles/2000/TheFlapOverReplacementMigration.aspx (accessed in April 2012)

Teitelbaum, Michael. S. 2004. "Western experiences with international migration in the context of population decline", Japanese Journal of Population, 2(1), 29-40.

Teitelbaum, Michael. S. and Jay M. Winter. 1985. The Fear of Population Decline. Orlando: Academic Press, Inc.

United Nations. 2000. Replacement Migration: Is it a Solution to Declining and Aging Populations? Population Division, New York.

Vatican 2006. "Address of His Holiness Benedict XVI to the Roman Curia offering them his Christmas greetings". Accessed at http://www.vatican.va/holy_father/benedict_xvi/speeches/2006/december/documents/hf_ben_xvi_spe_20 $\underline{061222 \text { curia-romana en.html }}$

VID. 2012. European demographic data sheet 2012. Vienna Institute of Demography and IIASA / Wittgenstein Centre for Denmography and Global Human Capital. Accessible at http://www.oeaw.ac.at/vid/datasheet/index.html 
Vos, Allison E. 2009. "Falling fertility rates: new challenges to the European welfare state." SocioEconomic Review 7(3): 475-503.

Wilson, Chris, Tomáš Sobotka, Lee Williamson, and Paul Boyle. 2010. “A simple method for estimating inter-generational replacement based on fertility and migration - European examples". ESRC Centre for Population Change, Working Paper 10. Available online at: http://www.cpc.ac.uk/publications/

Wilson, Chris and Lee Williamson. 2011. "Intergenerational replacement and migration in the countries and regions of the United Kingdom, 1971-2009." Population Trends 145 (Autumn 2011): 1-16. 
Figure 1: Lexis diagram displaying the "daughter's cohort" and the "mothers' cohorts" used in the computation of the Overall Replacement Ratio

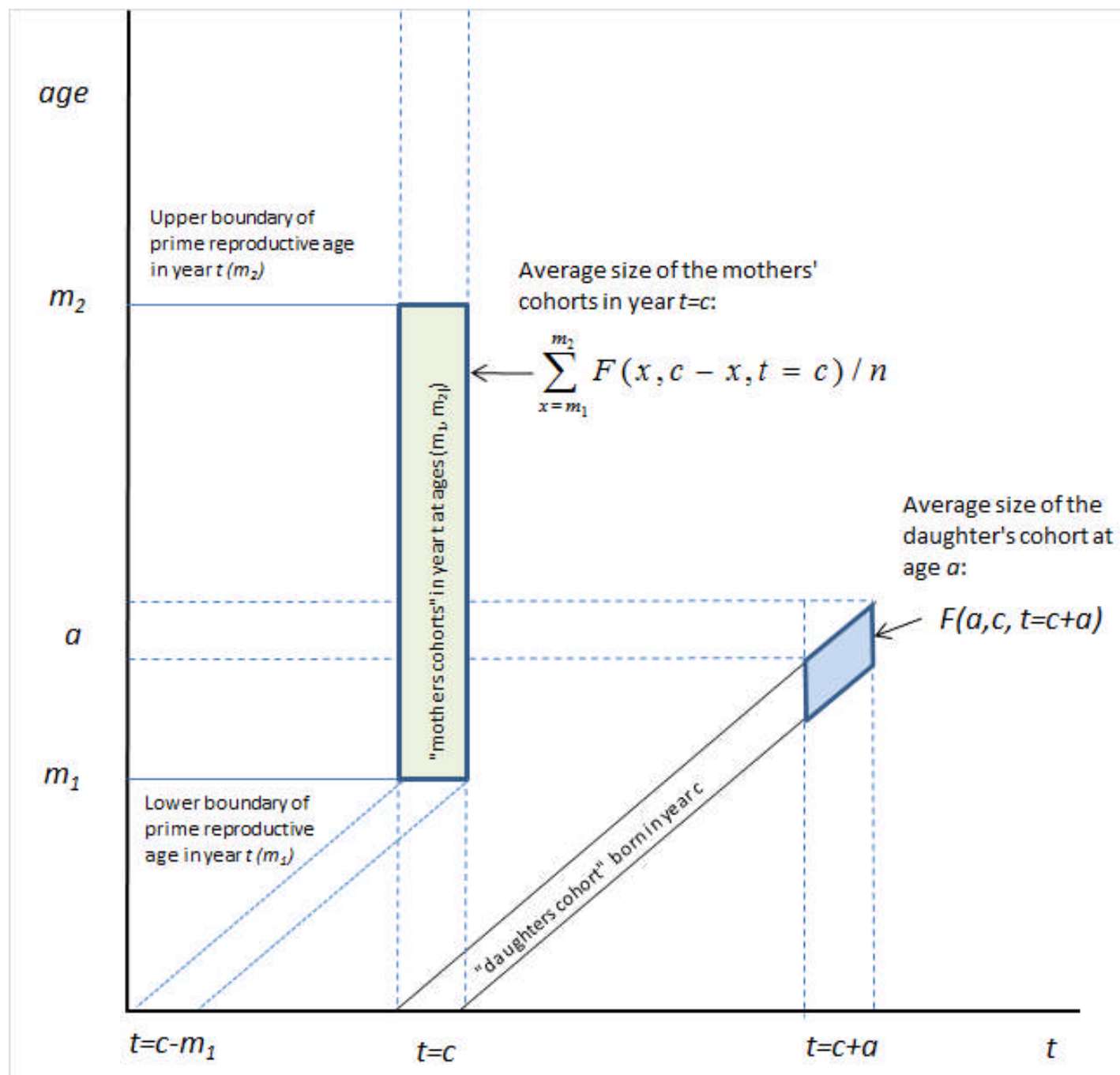


Figure 2: Overall replacement ratio by age for Austria, selected cohorts 1970 to 1995

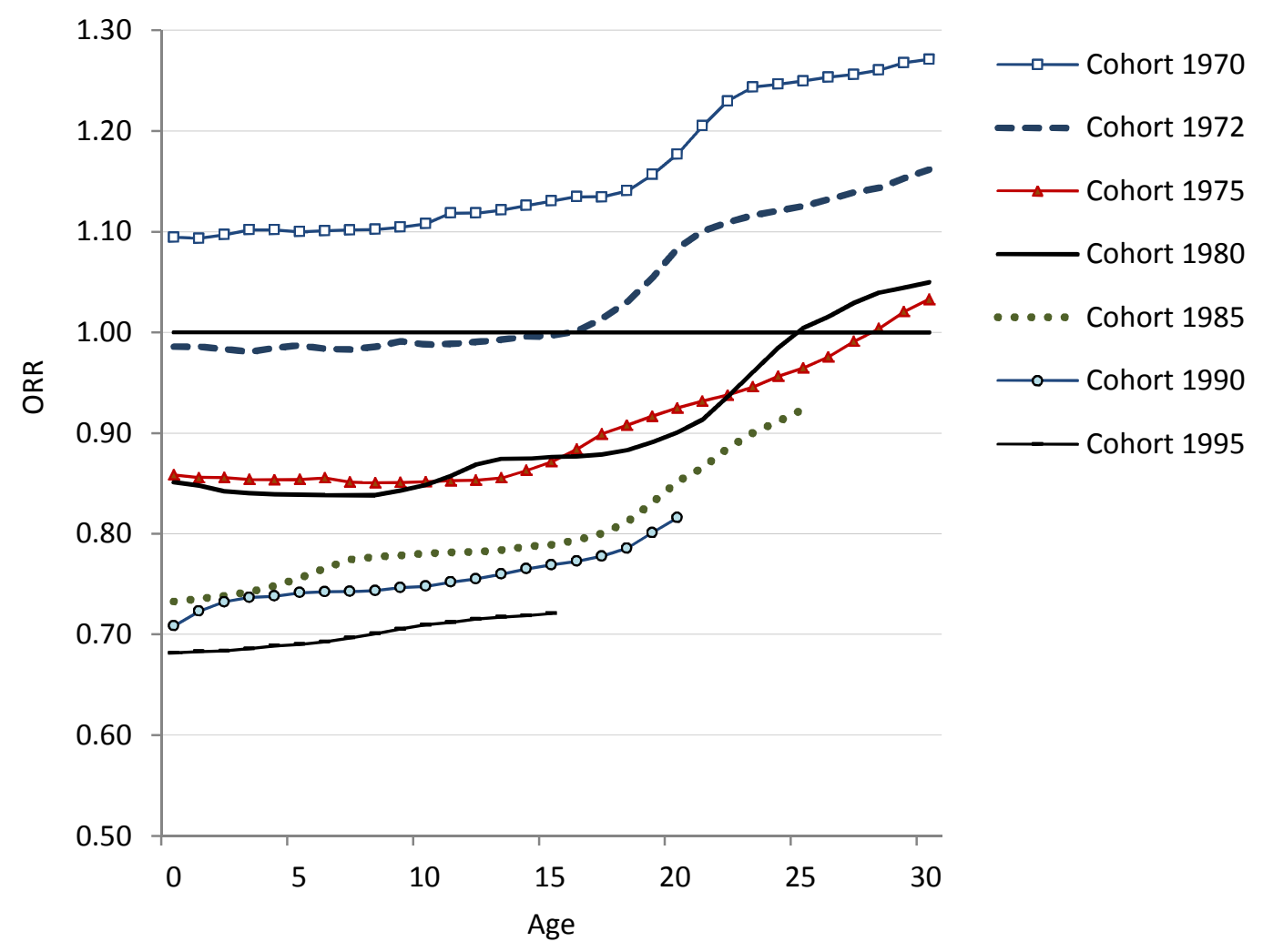

Source: Computed from Eurostat $(2010,2012)$ data 
Figure 3: Overall replacement ratio in comparison with conventional net reproduction rate and two indicators of birth and population replacement; Sweden 1950-2010

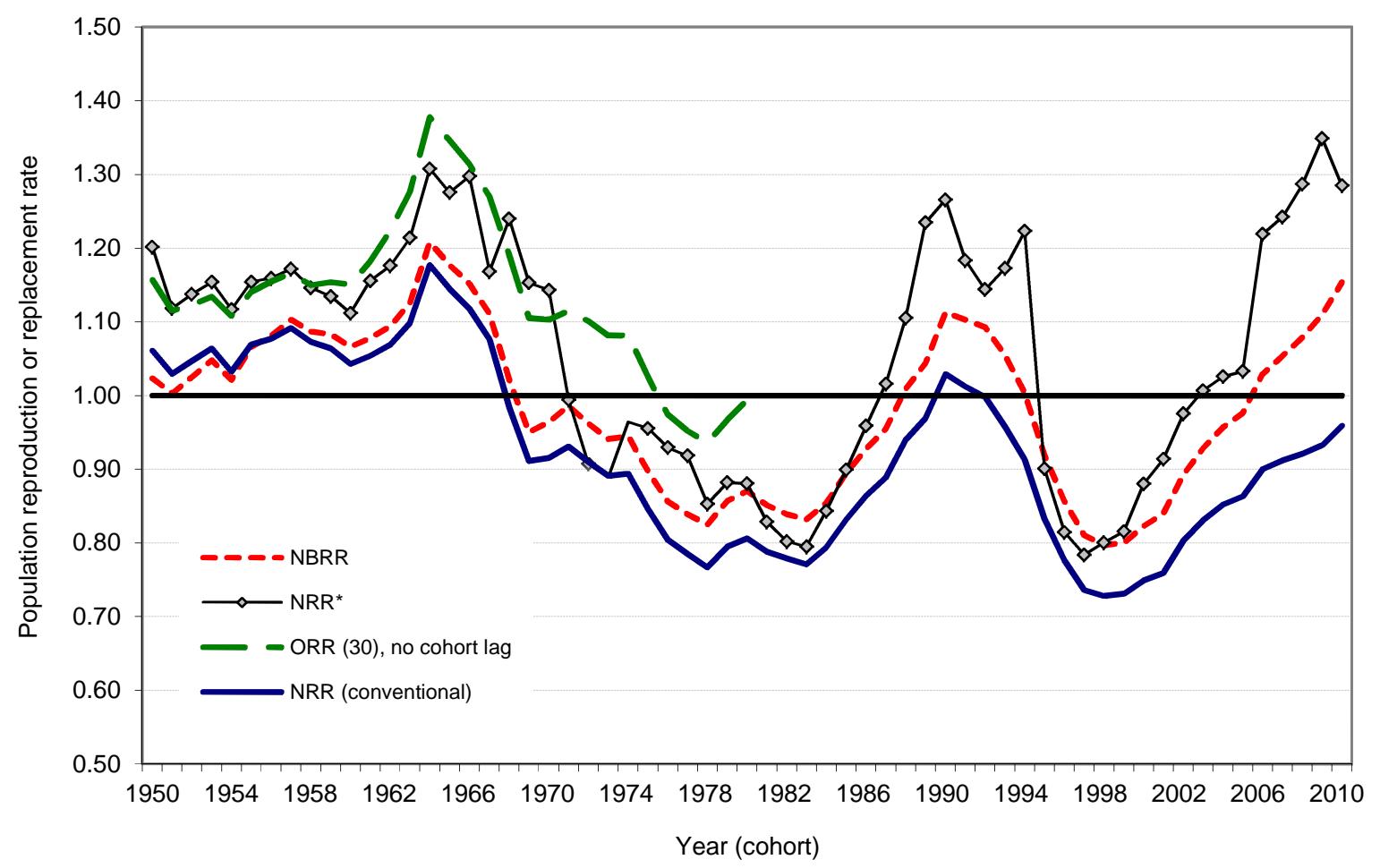

Notes: The following indicators are shown in the figure: The overall replacement ratio at age $30(\mathrm{ORR}(30))$ analysed in detail in this contribution; the conventional net reproductionr rate (NRR); the net reproduction rate in the presence of migration, NRR* (Preston and Wang 2007); and the net birth replacemet ratio, NBRR (del Rey Poveda and Cebrán-Villar 2010). Many thanks to Kryštof Zeman for computing time series of indicators used here (except the $\mathrm{NRR}^{*}$ ).

Sources: Computations based on Human Fertility Database (2012; data on age-specific fertility rates in 1900-2010), Eurostat (2012; data on female population by age, 1960-2011) and Human Mortality Database (2012; data on live births by sex, 1900-2010; data on female population by age, 1960-2011, and female mortality tables in 1900-2010). 
Figure 4: Overall replacement ratio by age for the European Union before the 2004 enlargement (EU-15), selected cohorts 1972-1995

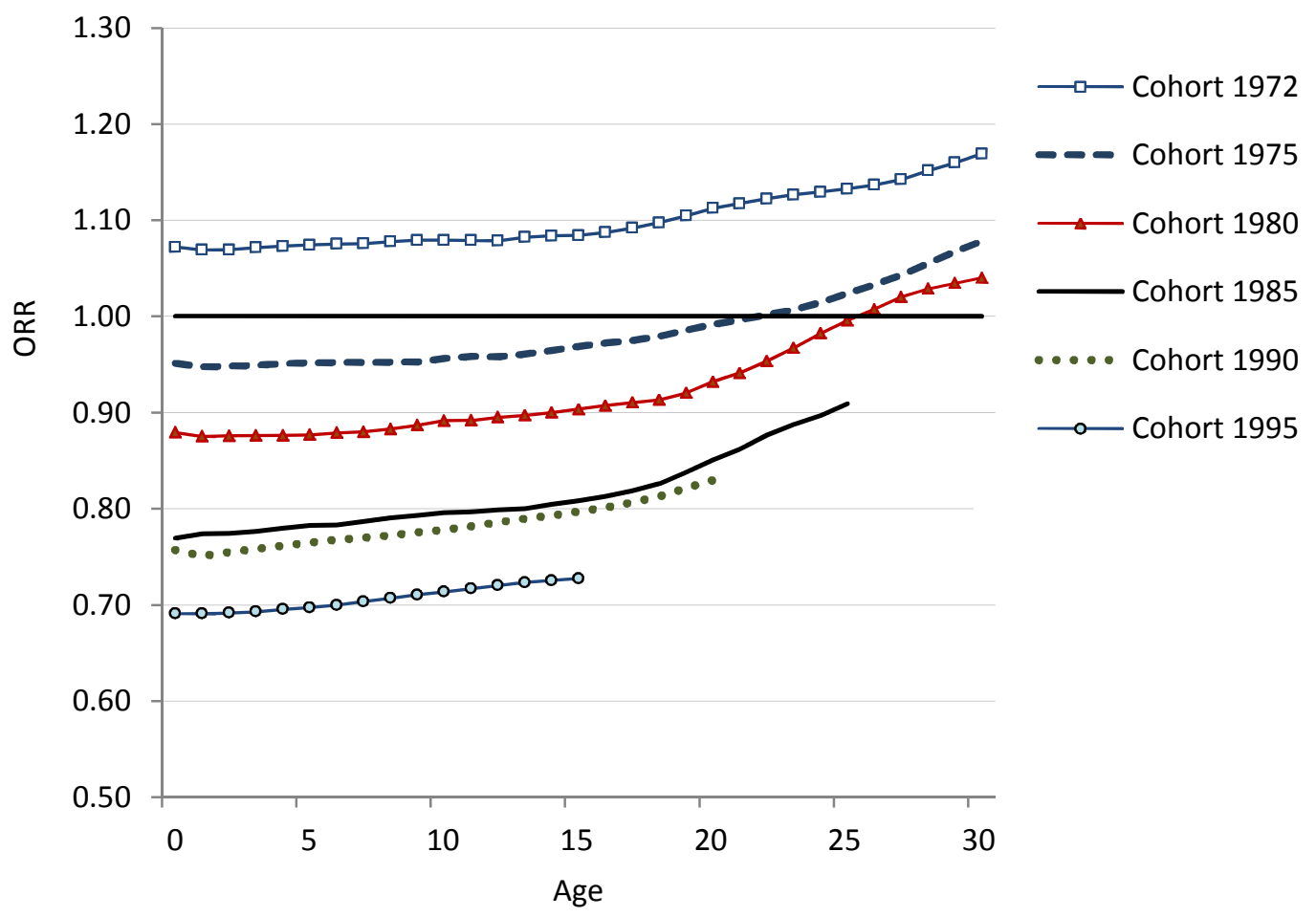

Sources: Computed from Eurostat $(2010,2012)$ data; data for Ireland based on the Human Mortality database (2012)

Note: The 15 countries are Austria, Belgium, Denmark, Finland, France, Germany, Greece, Ireland, Italy, Luxemburg, The Netherlands, Portugal, Spain, Sweden and The United Kingdom. 
Figure 5: Overall replacement ratio by age in twelve European countries; cohorts 1972-1995

\section{Western and Northern Europe}
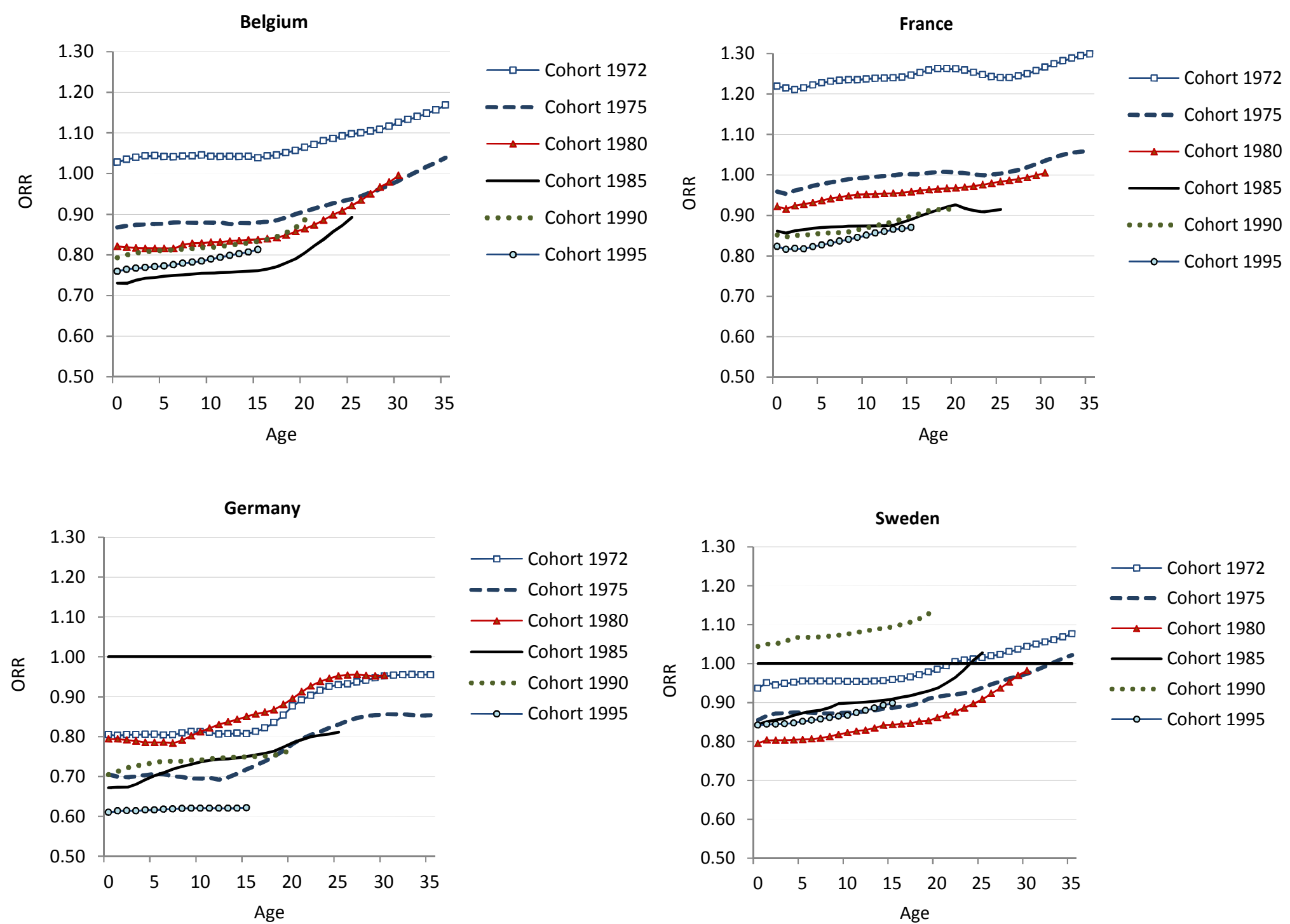
Western and Northern Europe continued
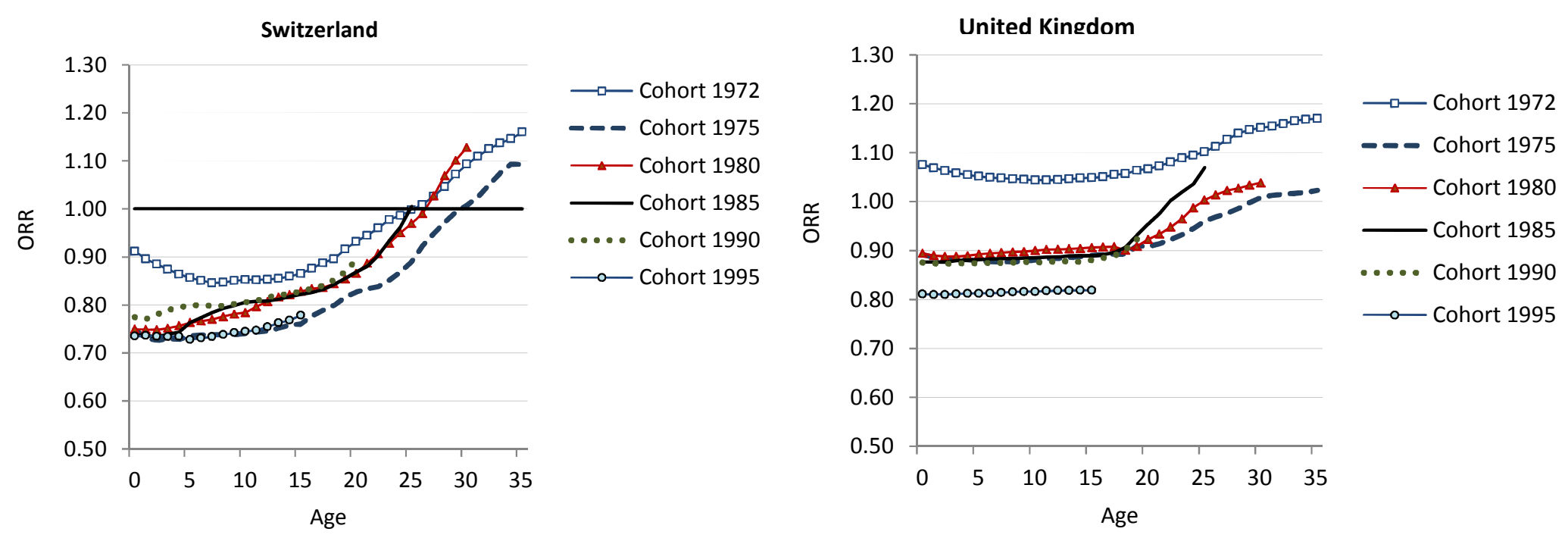

Southern Europe
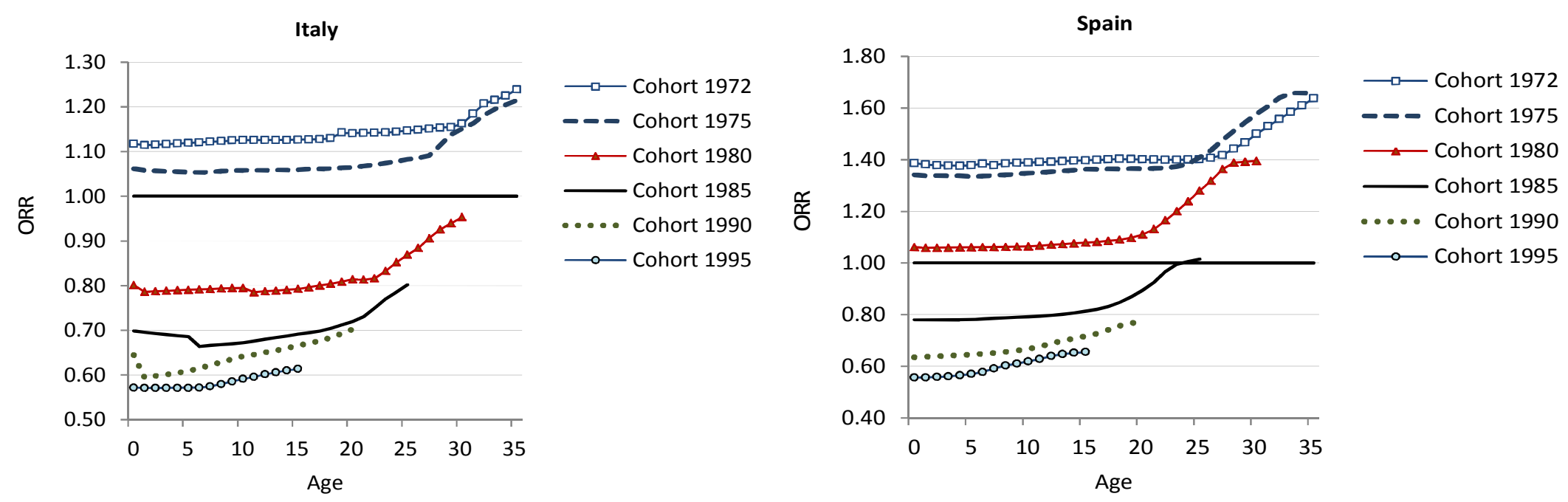


\section{Central Europe}
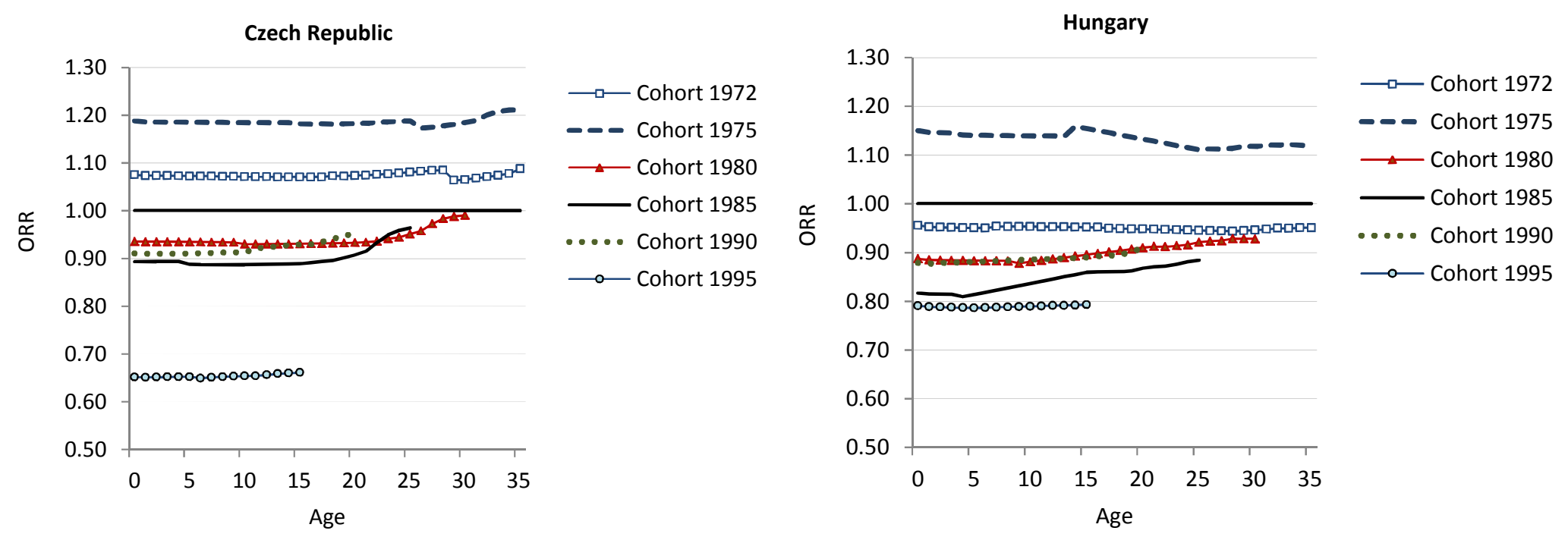

Eastern Europe
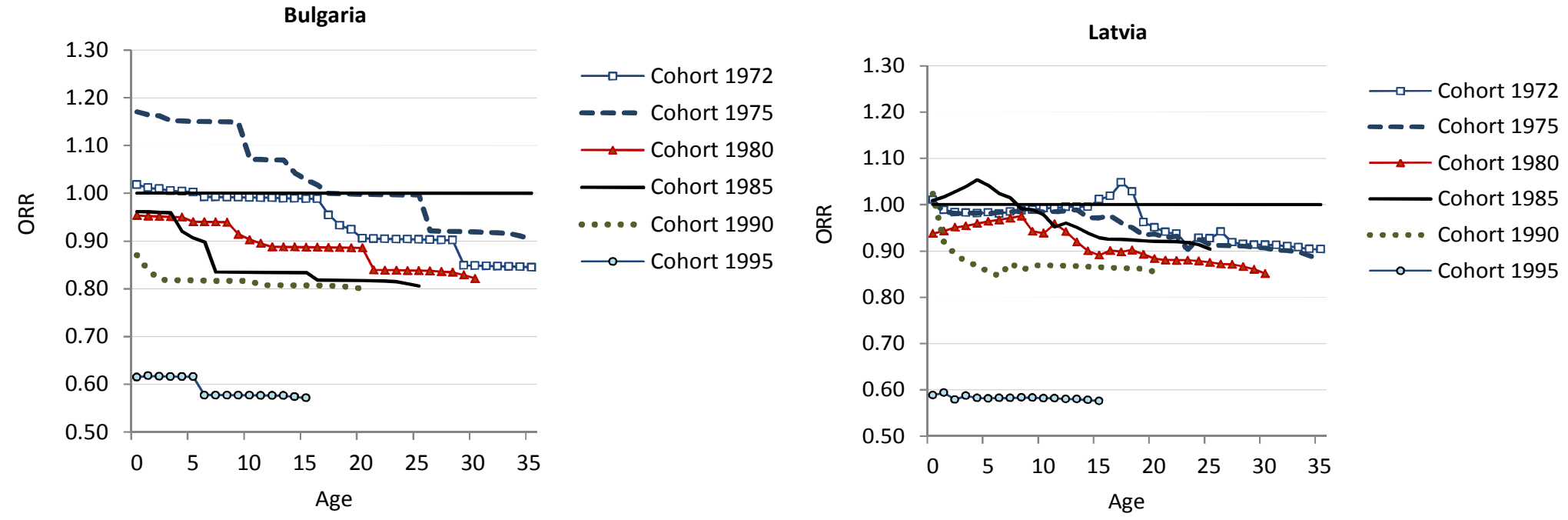

Source: Computed from Eurostat $(2010,2012)$ data. Note: Data for Spain plotted on different scale from other countries. 
Figure 6: Overall Replacement Ratio at age 0 and at age 30, cohorts 1975 (diamonds) and 1980 (triangles) in 18 European countries analysed in Table 2. Data for EU-15 as a whole displayed by enlarged markers.

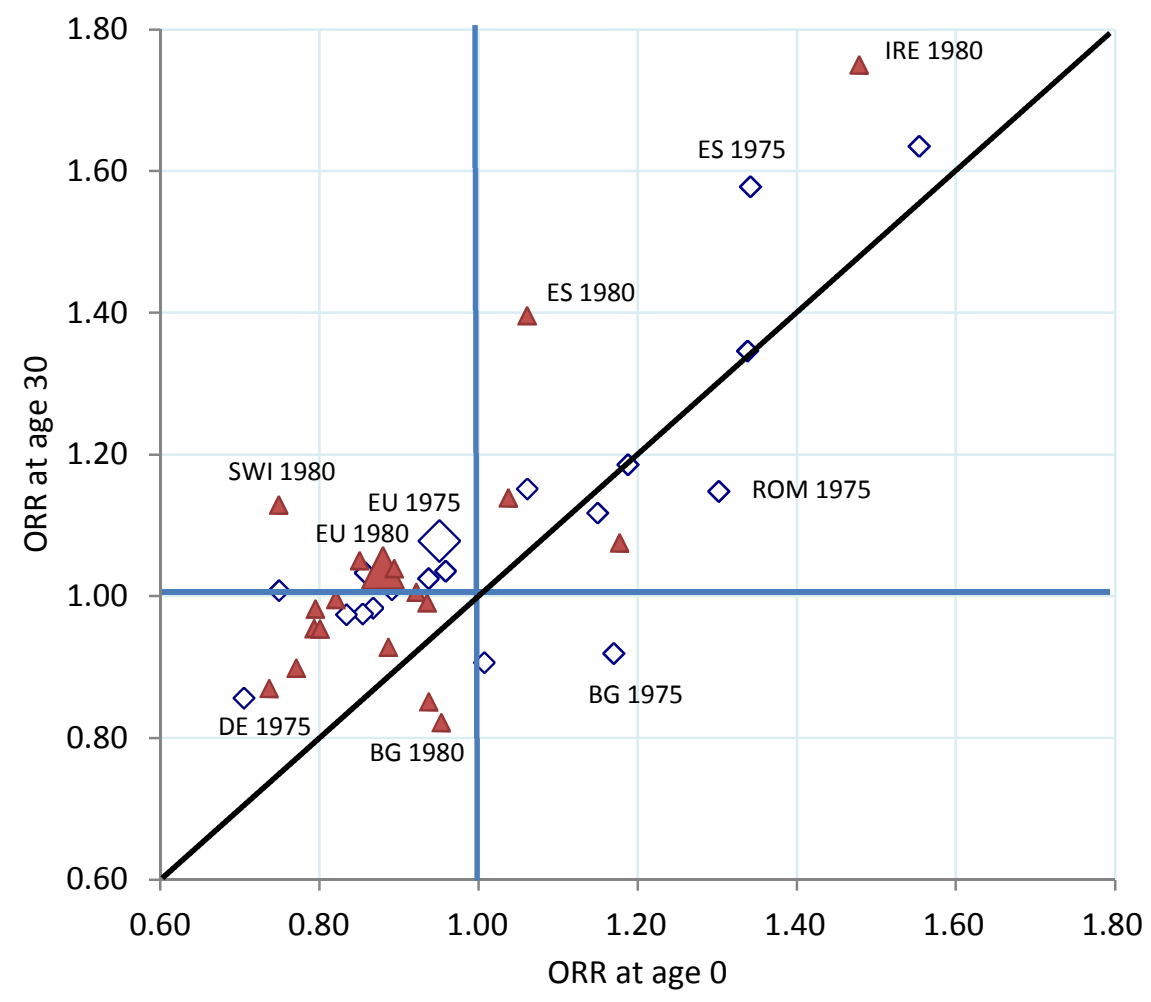

Sources: Computed from Eurostat $(2010,2012)$ data; data for Ireland based on the Human Mortality database (2012) 
Table 1: Selected indicators of population reproduction, birth replacement and population replacement

\begin{tabular}{|c|c|c|c|c|c|}
\hline \multirow[b]{2}{*}{ Indicator } & \multirow[b]{2}{*}{ Authors } & \multirow{2}{*}{$\begin{array}{l}\text { Type of } \\
\text { indicator }\end{array}$} & \multicolumn{3}{|c|}{ Components included } \\
\hline & & & Fertility & Mortality & Migration \\
\hline $\begin{array}{l}\text { Net } \\
\text { reproduction } \\
\text { rate (NRR) }\end{array}$ & $\begin{array}{l}\text { Kuczynski } \\
\text { (1928) }\end{array}$ & $\begin{array}{l}\text { Synthetic } \\
\text { period } \\
\text { measuring } \\
\text { population } \\
\text { reproduction }\end{array}$ & YES - period $(t)$ & YES - period $(t)$ & NO \\
\hline $\begin{array}{l}\text { Net } \\
\text { reproduction } \\
\text { rate in the } \\
\text { presence of } \\
\text { migration } \\
\left(N R R^{*}\right)\end{array}$ & $\begin{array}{l}\text { Preston and } \\
\text { Wang (2007); } \\
\text { similar concept } \\
\text { by Hyrenius } \\
\text { (1951) }\end{array}$ & $\begin{array}{l}\text { Synthetic } \\
\text { period } \\
\text { measuring birth } \\
\text { replacement }\end{array}$ & YES - period $(t)$ & YES - period $(t)$ & YES - period $(t)$ \\
\hline $\begin{array}{l}\text { Combined } \\
\text { reproduction } \\
(C R)\end{array}$ & $\begin{array}{l}\text { Ediev et al. } \\
(2007,2012)\end{array}$ & $\begin{array}{l}\text { Synthetic } \\
\text { period } \\
\text { measuring birth } \\
\text { replacement }\end{array}$ & $\begin{array}{l}\text { YES - period }(\mathrm{t}) \text {; } \\
\text { Differentiates } \\
\text { between } \\
\text { fertility of } \\
\text { 'native' and } \\
\text { migrant women }\end{array}$ & YES - period $(t)$ & YES - period $(t)$ \\
\hline $\begin{array}{l}\text { Net birth } \\
\text { replacement } \\
\text { ratio (NBRR) }\end{array}$ & $\begin{array}{l}\text { Ortega and del } \\
\text { Rey (2007), del } \\
\text { Rey Poveda and } \\
\text { Cebrán-Villar } \\
\text { (2010) }\end{array}$ & $\begin{array}{l}\text { Quasi-period } \\
\text { measuring birth } \\
\text { replacement } \\
\text { (observed } \\
\text { period births in } \\
\text { t vs. cohort size } \\
\text { of mothers at } \\
\text { birth) }\end{array}$ & $\begin{array}{l}\text { YES - period }(\mathrm{t}) / \\
\text { "cohort of } \\
\text { mothers" at } \\
\text { birth } \\
\text { combination }\end{array}$ & $\begin{array}{l}\text { Indirectly - } \\
\text { cohort } \\
\text { (modifying the } \\
\text { size of } \\
\text { "mothers' } \\
\text { cohort" prior to } \\
\text { year t) }\end{array}$ & $\begin{array}{l}\text { Indirectly - } \\
\text { cohort } \\
\text { (modifying the } \\
\text { size of } \\
\text { "mothers' } \\
\text { cohort" prior to } \\
\text { year t) }\end{array}$ \\
\hline $\begin{array}{l}\text { Overall } \\
\text { replacement } \\
\text { ratio (ORR) }\end{array}$ & $\begin{array}{l}\text { Wilson et al } \\
\text { (2010, this } \\
\text { article); similar } \\
\text { concepts by } \\
\text { Dalla Zuanna } \\
\text { (2008) and } \\
\text { Sobotka (2008) }\end{array}$ & $\begin{array}{l}\text { Quasi-cohort } \\
\text { measuring } \\
\text { population } \\
\text { replacement } \\
\text { (cohort born in } \\
\text { t subsequently } \\
\text { modified by } \\
\text { migration) }\end{array}$ & $\begin{array}{l}\text { YES - period }(\mathrm{t}) / \\
\text { "cohort of } \\
\text { mothers" in } \mathrm{t} \\
\text { combination }\end{array}$ & $\begin{array}{l}\text { YES - cohort: } \\
\text { affecting cohort } \\
\text { size after year t }\end{array}$ & $\begin{array}{l}\text { YES - cohort: } \\
\text { affecting cohort } \\
\text { size after year } \mathrm{t}\end{array}$ \\
\hline
\end{tabular}


Table 2: Overall replacement ratio at ages 0 and 30 in female birth cohorts 1975 and 1980 (selected European countries)

\begin{tabular}{|c|c|c|c|c|c|c|c|c|}
\hline & \multicolumn{2}{|c|}{ ORR at age 0} & \multicolumn{2}{|c|}{ ORR at age 30} & \multicolumn{2}{|c|}{$\begin{array}{c}\text { Abs. increase in } \\
\text { ORR between ages } \\
0 \text { and } 30\end{array}$} & \multicolumn{2}{|c|}{$\begin{array}{c}\text { Relative change } \\
\text { (index): ORR at } \\
\text { age } 30 \text { / ORR at } \\
\text { age } 0 \\
\end{array}$} \\
\hline & C 1975 & C 1980 & C 1975 & C 1980 & C 1975 & C 1980 & C 1975 & C 1980 \\
\hline EU-15 & 0.95 & 0.88 & 1.08 & 1.04 & 0.13 & 0.16 & 1.13 & 1.18 \\
\hline \multicolumn{9}{|l|}{ Western Europe } \\
\hline Belgium & 0.87 & 0.82 & 0.98 & 1.00 & 0.11 & 0.17 & 1.13 & 1.21 \\
\hline France & 0.96 & 0.92 & 1.04 & 1.01 & 0.08 & 0.08 & 1.08 & 1.09 \\
\hline Ireland & 1.55 & 1.48 & 1.63 & 1.75 & 0.08 & 0.27 & 1.05 & 1.18 \\
\hline Netherlands & 0.83 & 0.77 & 0.97 & 0.90 & 0.14 & 0.13 & 1.17 & 1.16 \\
\hline UK & 0.89 & 0.89 & 1.01 & 1.04 & 0.12 & 0.14 & 1.13 & 1.16 \\
\hline \multicolumn{9}{|l|}{ Nordic countries } \\
\hline Denmark & 0.94 & 0.74 & 1.02 & 0.87 & 0.09 & 0.13 & 1.09 & 1.18 \\
\hline Sweden & 0.85 & 0.80 & 0.97 & 0.98 & 0.12 & 0.19 & 1.14 & 1.23 \\
\hline \multicolumn{9}{|c|}{ German-speaking } \\
\hline Austria & 0.86 & 0.85 & 1.03 & 1.05 & 0.17 & 0.20 & 1.20 & 1.23 \\
\hline Germany & 0.71 & 0.79 & 0.86 & 0.95 & 0.15 & 0.16 & 1.21 & 1.20 \\
\hline Switzerland & 0.75 & 0.75 & 1.01 & 1.13 & 0.26 & 0.38 & 1.34 & 1.50 \\
\hline \multicolumn{9}{|c|}{ Southern Europe } \\
\hline Italy & 1.06 & 0.80 & 1.15 & 0.95 & 0.09 & 0.15 & 1.08 & 1.19 \\
\hline Portugal & 1.34 & 1.04 & 1.35 & 1.14 & 0.01 & 0.10 & 1.01 & 1.10 \\
\hline Spain & 1.34 & 1.06 & 1.58 & 1.40 & 0.24 & 0.33 & 1.18 & 1.31 \\
\hline \multicolumn{9}{|c|}{ Central \& Eastern Europe } \\
\hline Hungary & 1.15 & 0.89 & 1.12 & 0.93 & -0.03 & 0.04 & 0.97 & 1.05 \\
\hline Czech Republic & 1.19 & 0.94 & 1.19 & 0.99 & 0.00 & 0.05 & 1.00 & 1.06 \\
\hline Bulgaria & 1.17 & 0.95 & 0.92 & 0.82 & -0.25 & -0.13 & 0.79 & 0.86 \\
\hline Latvia & 1.01 & 0.94 & 0.91 & 0.85 & -0.10 & -0.09 & 0.90 & 0.91 \\
\hline Romania & 1.30 & 1.18 & 1.15 & 1.07 & -0.15 & -0.10 & 0.88 & 0.91 \\
\hline
\end{tabular}

Sources: Computed from Eurostat (2010, 2012) data; data for Ireland based on the Human Mortality database (2012) 


\section{Appendix: Comparing the Overall Replacement Ratio, the Net Reproduction Rate and the Gross Reproduction Rate - Sweden 1850-2010}

A key assumption underlying the overall replacement ratio is that the age-pattern of fertility only needs to be taken account in a very elementary way, by indicating the upper and lower bounds of the main childbearing ages. The validity of this assumption can be examined by comparing the conventional gross reproduction rate (GRR) with the ORR calculated at birth (i.e., the number of births in a given year divided by the average size of the mothers' birth cohorts in that year).

Figure A1 presents the GRR and the ORR(birth) defined in three different ways for Sweden from 1852 to 2005 . All lines are five-point moving averages of the annual values to avoid unusual fluctuations. It is clear that the suitability of the three definitions of mothers' cohorts (20-35, 20-40 and 20-45) varies over time. However, at every point the best fitting ORR(birth) comes very close to the GRR. In fact, over the whole 153-year span the best fitting value is never as much as three percent above or below the GRR. Table A1 gives the best fitting age-range in each period. From 1852 to 1911 the widest age-range for mothers' ages (20-45) gives the best fit, while for the next thirty years (1912-1942) 20-40 is to be preferred. Since the 1940s the age-range of choice has varied, but from 1967 to 1998, i.e. throughout the period of main interest in this paper, 20-35 is the best fitting, and thus is used in all our calculations related to replacement migration.

The pattern of change in the fit makes good sense when reflecting on what is known about the age pattern of fertility. During the late $19^{\text {th }}$ and early $20^{\text {th }}$ centuries fertility was relatively high right through the reproductive ages, so $20-45$ is a logical best fit. As fertility decline set in, rates dropped most sharply at the oldest ages, so 20-40 became more suitable. As fertility fell to still lower levels and became concentrated in the younger age-groups, 20-35 came to the fore as the best fit. And finally, with the increasing delay of fertility after the 1960s baby boom, a wider range fits best. The exact dates for which each age-range is to be preferred vary from country to country, but the overall pattern of change is broadly similar in much of Western Europe, and for the period of most interest here 20-35 is the age-range of choice.

A further comparison that helps illuminate the potential value of the overall replacement ratio is with the net reproduction rate. Figure A2 shows the annual (period) NRR for Sweden from 
1852 to 1976, along with the ORR at age 30 for cohorts born 1852-1976. Thirty is chosen for the ORR as an approximate indicator of the mean age at net reproduction. Again, both lines are five-point moving averages. The two measures can be expected to differ somewhat because the cohorts born in each year experience lower mortality than was prevalent in the year of their birth. Thus, other things being equal, the $\operatorname{ORR}(30)$ line could be expected to lie slightly above the NRR because of this mortality difference. The main factor leading to divergence between the two lines, however, is migration. Between about 1860 and World War I roughly one-third of all the natural increase in Sweden was lost through emigration, principally to the United States. This explains why the ORR(30) line lies well below that for the NRR over these decades. However, from the inter-war period on, Sweden became a net 'importer' of people and, as Figure A2 clearly shows, there is switch-over with the ORR(30) above the NRR for cohorts born from the early $20^{\text {th }}$ century on. The increasing gap between the two lines at the right-hand end of the graph is the feature of interest most relevant to this paper, as replacement migration becomes a more and more significant factor. Taken as a whole, the graph suggests that the ORR can make a valuable addition to the demographer's toolkit: the GRR indicates the level of fertility, the NRR reduces this to show the impact of mortality, while the ORR incorporates in addition the impact of migration. 
Figure A1: Gross Reproduction Rate (GRR) and three versions of the Overall Replacement Ratio (ORR) at birth, with varying definitions of mothers' age range, 20-35, 20-40 and 20-45, Sweden, 1852-2005

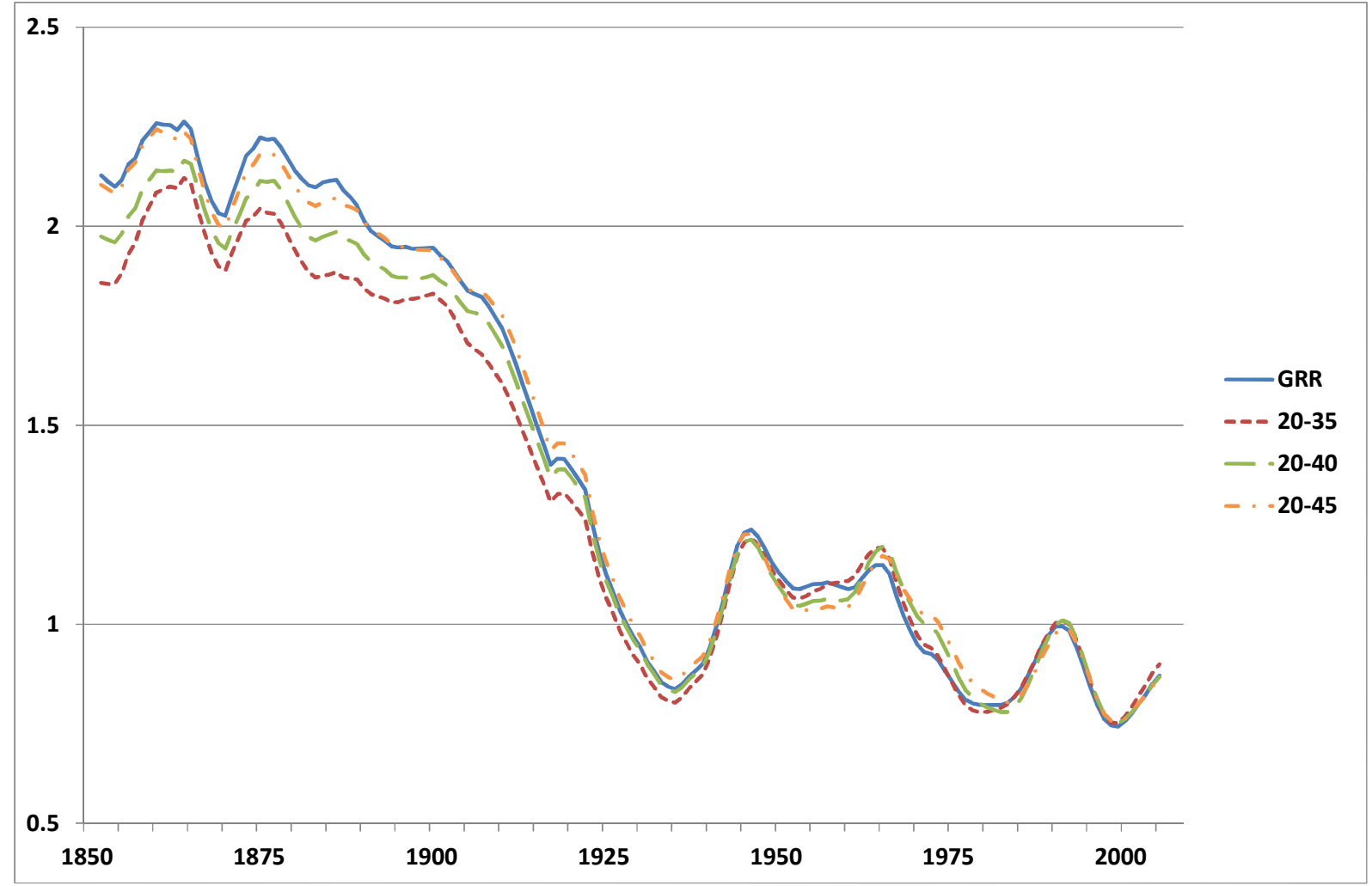

Note: All series are five-point moving averages of annual series.

Data sources: Human Fertility Database (2011), Festy (1979). 
Figure A2: Overall replacement ratio at age 30 and net reproduction rate in Sweden, 18521976

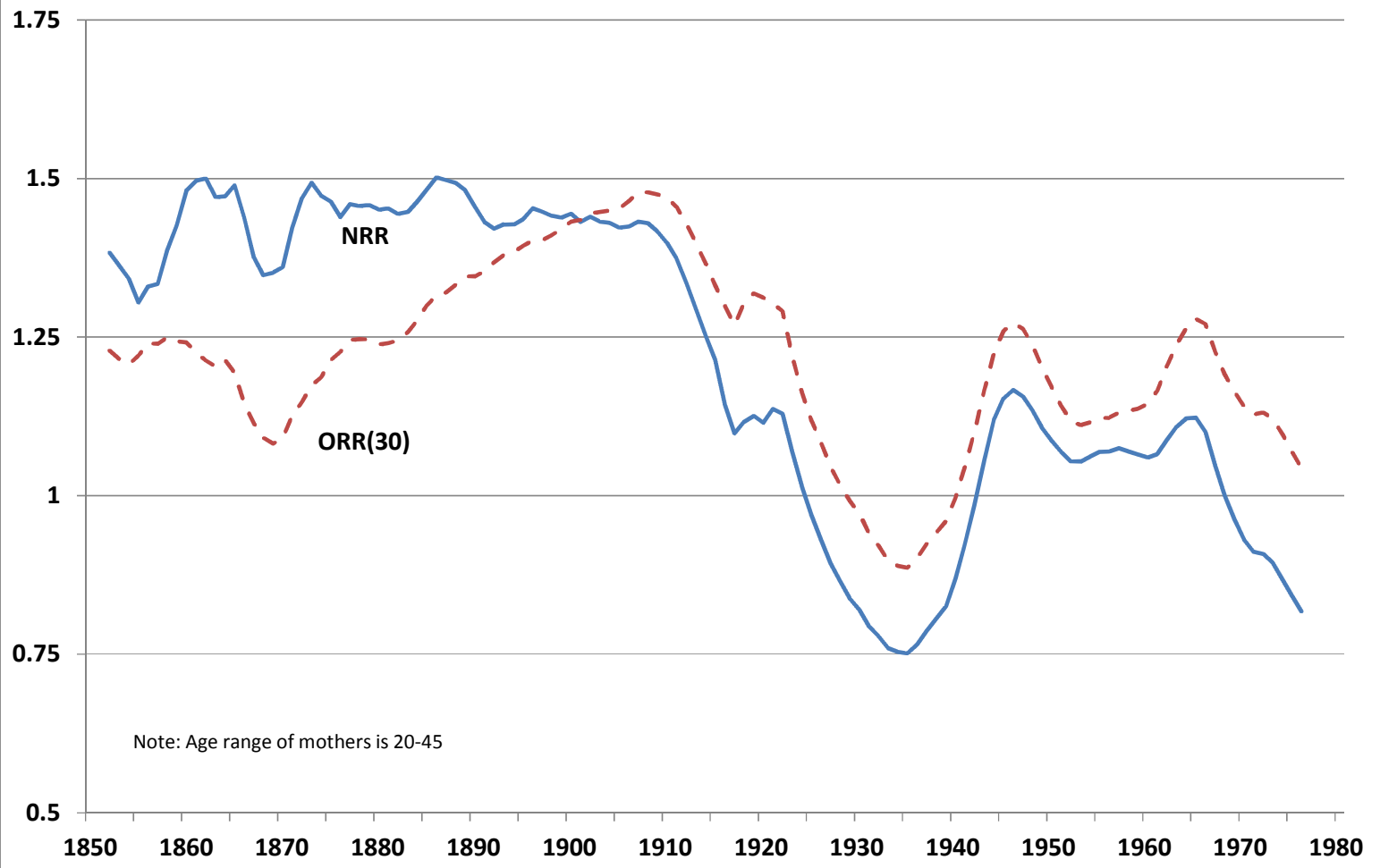

Notes: Both series are five-point moving averages of annual series. ORR is calculated with mothers' age range set at 20-45.

Data sources: Festy (1979), Human Fertility Database (2011), and Human Mortality Database (2011). 
Table A1: Best-fitting definition of mothers' age range for ORR(birth) for fitting to gross reproduction rate and mean percentage error, Sweden, 1852-2005

\begin{tabular}{lcc}
\hline Period & Best fitting range & Mean difference (percent) \\
\hline $1852-1911$ & $20-45$ & 1.10 \\
$1912-1942$ & $20-40$ & 1.42 \\
$1943-1947$ & $20-45$ & 0.96 \\
$1948-1962$ & $20-35$ & 1.81 \\
$1963-1966$ & $20-45$ & 2.80 \\
$1967-1998$ & $20-35$ & 1.43 \\
$1999-2005$ & $20-40$ & 0.52 \\
\hline
\end{tabular}

Data sources: See Figure A1.

Note: ORR and GRR values used for fitting are five-year moving averages of annual values. 